\title{
LA LEY CATALANA DE CAMBIO CLIMÁTICO TRAS LA SENTENCIA DEL TRIBUNAL CONSTITUCIONAL. ESTUDIO DE LAS REPERCUSIONES DE LA SENTENCIA Y SU EVOLUCIÓN LEGISLATIVA ${ }^{1}$
}

\section{THE CATALAN CLIMATE CHANGE ACT AFTER THE JUDGMENT OF THE CONSTITUTIONAL COURT. A STUDY ON THE CONSEQUENCES OF THE CASE AND ITS LEGISLATIVE EVOLUTION}

\author{
AITANA DE LA VARGA PASTOR \\ Profesora Agregada de Derecho Administrativo \\ Universitat Rovira i Virgili \\ aitana.delavarga@urv.cat
}

Fecha de recepción: 22 de mayo de 2020 / Fecha de aceptación: 26 de junio de 2020

\begin{abstract}
RESUMEN: Este trabajo versa sobre la Ley 16/2017, de 1 de agosto, de cambio climático de Catalunya y su situación tres años después de su promulgación, en 2020. Para ello, se parte del evidente cambio de escenario envuelto por la emergencia climática y de la situación y el contexto en el que se enmarca esta normativa. El objeto principal del trabajo yace en el estudio de la evolución de esta ley tras la Sentencia de Tribunal Constitucional 87/2019 que resuelve el recurso de inconstitucionalidad de carácter competencial interpuesto contra un gran número de artículos de la ley. El foco del trabajo se pone en los artículos que han sido impugnados y en el desarrollo legislativo y reglamentario de la ley, con el objetivo de dilucidar si la ley sigue siendo aplicable y si mantiene su esencia y la ambición que inicialmente la caracterizaba.
\end{abstract}

\footnotetext{
${ }^{1}$ Este trabajo ha sido desarrollado en el marco del proyecto de investigación Constitución climática global: gobernanza y Derecho en un contexto complejo, financiado por el Ministerio de Economía y Competitividad para el trienio 2017-2019 (proyecto DER2016-80011-P; investigadores principales: Jordi Jaria-Manzano y Susana Borràs Pentinat).
} 
RESUM: Aquest treball versa sobre la Llei 16/2017, d'1 d'agost, de canvi climàtic de Catalunya i la seva situació tres anys després de la seva promulgació, el 2020. Per a això, es parteix de l'evident canvi d'escenari envoltat per l'emergència climàtica i de la situació i el context en el que s'emmarca aquesta normativa. L'objecte principal del treball rau en l'estudi de l'evolució d'aquesta llei després de la Sentència de Tribunal Constitucional $87 / 2019$ que resol el recurs d'inconstitucionalitat de caràcter competencial interposat contra un gran número d'articles de la llei. El focus del treball es posa en els articles que han sigut impugnats y en el desenvolupament legislatiu i reglamentari de la llei, con l'objectiu de dilucidar si la llei segueix sent aplicable i si manté la seva essència i l'ambició que inicialment la caracteritzava.

ABSTRACT: This work deals with Law 16/2017, of August 1, on climate change in Catalonia and its situation three years after its enactment, in 2020. To do this, we start with the evident change of scenery involved in the climate and environmental emergency, the situation and context in which this regulation is framed. The main object of the work lies in the study of the evolution of this law after the Constitutional Court Judgment 87/2019 that resolves the appeal of unconstitutionality of competence filed against a large number of articles of the law. The focus of the work is placed on the articles that have been contested and on the legislative and regulatory development of the law, with the aim of elucidating whether the law continues to be applicable and whether it maintains its essence and the ambition that originally characterized it.

PALABRAS CLAVE: Cambio climático - Mitigación - Adaptación - Legislación ambiental - Transición energética.

PARAULES CLAU: Canvi climàtic - Mitigació - Adaptació - Legislació ambiental - Transició energètica

KEYWORDS: Climate change - Mitigation - Adaptation - Environmental legislation - Energy transition.

SUMARIO: I. INTRODUCCIÓN; II. ¿CUÁL ES EL ESCENARIO ACTUAL?; 1. La emergencia climática. Situación global; 2. La situación en el ámbito internacional; 3. La situación en el ámbito de la Unión europea; 4. La situación en el estado español; 5. La situación en Catalunya; III. EL DEBATE COMPETENCIAL EN RELACIÓN CON EL CAMBIO CLIMÁTICO. LA RECENTRALIZACIÓN DE COMPETENCIAS; IV. ¿CUÁLES SON LAS PRINCIPALES CUESTIONES DE LA LCCC DE LAS QUE SE DUDA DE SU CONSTITUCIONALIDAD? ¿CÓMO SE RESUELVEN?; 1. La mitigación del cambio climático: los objetivos y las herramientas para su logro; a) Los presupuestos del carbono; b) Los objetivos de reducción de emisión de GEl; 2. La adaptación al cambio climático: la planificación puesta en duda; 3. Las 
políticas sectoriales; a) Las aguas; b) La transición energética: objetivos, planificación y medios cuestionados; c) Edificios y edificaciones; d) Infraestructuras; e) Transporte y movilidad; 4. Los impuestos ambientales de mitigación y adaptación del cambio climático; 5. La Comisión interdepartamental del Cambio climático; 6. El Fondo Climático; 7. El régimen de comercio de derechos de emisión. V. CONCLUSIONES; VI. BIBLIOGRAFÍA.

\section{INTRODUCCIÓN}

La ley 16/2017, de 1 de agosto, de cambio climático (en adelante, LCCC) se erigió como la primera ley autonómica en el estado español que afrontaba uno de los grandes retos con los que lidia la humanidad, el cambio climático. ${ }^{2}$ Dicha ley daba continuidad a las políticas de cambio climático, que ya hacía años que Catalunya iba desarrollando y aplicando, y suponía la culminación de este proceso. Esta ley se promulgó teniendo en cuenta las directrices de la Unión europea y los Acuerdos de París ${ }^{3}$, en especial tomando el protagonismo que, como subnational entity, se otorga a estos sujetos para afrontar el cambio climático, y tomar aquellas medidas necesarias y adecuadas para frenarlo. Además, el propio estado español carecía de norma alguna al respecto.

Esta ley acoge y concreta los objetivos de reducción de las emisiones de gases de efecto invernadero, con el fin de mitigar el cambio climático $\mathrm{y}$, en ambos casos, se proponen instrumentos de planificación y otras medidas y herramientas, como veremos, para lograrlos. La transición energética hacia las emisiones $100 \%$ neutras de carbono es otro de los hitos que plantea. Asimismo, regula la adaptación al cambio climático y contempla la intervención en distintas políticas sectoriales cruciales. ${ }^{4}$

En definitiva, destaca por plantearse unas finalidades muy ambiciosas y expansivas, con el objetivo último de reducir las emisiones de GEI y la

\footnotetext{
2 De esta novedad se hace eco Marina Rodriguez Beas en la crónica "Derecho y políticas ambientales en Catalunya (segundo semestre 2017), RCDA Vol IX Núm. 2 (2017), pp. 5 y ss.

${ }^{3}$ Véase entre otros Susana Borrás Pentinat y Paola Villacencio Calzadilla (eds.), El Acuerdo de París sobre cambio climático: ¿Un acuerdo histórico o una oportunidad perdida?, Arazandi, Cizur Menor, 2018.

${ }^{4}$ Nos remitimos a los artículos de Marina Rodríguez Beas, "La incidencia del acuerdo de París en las políticas públicas catalanas frente al cambio climático: la ley 16/2017, de 1 de agosto, del cambio climático", RCDA, vol. 9, núm. 2 (2018) y, Aitana De la Varga Pastor, "Estudio de la ley catalana 16/2017, de 1 de agosto, de cambio climático, y análisis comparativo con otras iniciativas legislativas subestatales, RCDA, vol. 9, núm. 2 (2018), donde se analiza esta ley, entre otros.
} 
vulnerabilidad ${ }^{5}$ ante los efectos del cambio climático. Para ello se fijan herramientas, se crean órganos administrativos y se incide en las distintas políticas sectoriales, destacando el sector energético, en el que se plantea la transición energética hacia la producción de energía limpia. Se apuesta por la imposición ambiental y la creación de fondos, entre otras.

Esta ley fue recurrida ante el Tribunal Constitucional mediante recurso de inconstitucionalidad, interpuesto por el entonces presidente del Gobierno de España, que fue admitido a trámite. ${ }^{6}$ Esto conllevó la suspensión de la vigencia y de la aplicación de los preceptos impugnados desde la fecha de interposición del recurso para las partes del proceso y desde su publicación del correspondiente edicto en el Boletín Oficial del Estado, para los terceros. ${ }^{7}$ Sin embargo, el 21 de marzo de $2018^{8}$ se decidió levantar la suspensión de todos los artículos, salvo el relativo al fracking. ${ }^{9}$ Finalmente, el 20 de junio de 2019 el Tribunal Constitucional dictó sentencia núm. 87/2019 (en adelante, STC). ${ }^{10}$ Dicha sentencia, como analizaremos, conservó y validó algunos de los artículos impugnados, otros los interpretó conforme a la Constitución española y, finalmente, otros más los anuló, por entender que Cataluña estaba invadiendo competencias que, acorde con su interpretación, corresponden al Estado.

\footnotetext{
${ }^{5}$ Véase José Francisco Alenza García, "Vulnerabilidad ambiental y vulnerabilidad climática" en $R C D A$, vol. 10 núm. 1, 2019, pp. 1-46 y Andrea Lampis,, "Vulnerabilidad y adaptación al cambio climático: debates acerca del concepto de vulnerabilidad y su medición", en Cuadernos de Geografía, vol. 22, no 2, 2013, pp. 17-33.

${ }^{6}$ El Pleno del Tribunal Constitucional, por providencia de 28 de noviembre de 2017, acordó admitir a trámite el recurso de inconstitucionalidad núm. 5334-2017, promovido por el presidente del Gobierno, contra los artículos 2.2.e), 4.e), 5, 6, 7, 8, 10, 11, 16.3, 19, 21.4, 24.3, 24.4, 40 a 50, 51 (inciso final del apartado 1 y letras a) y b) del apartado 3), 52.1, 52.3; las disposiciones adicionales primera, segunda, tercera y séptima; la disposición transitoria tercera; y las disposiciones finales quinta y sexta.

${ }^{7}$ Esta suspensión se produjo con la admisión del mencionado recurso de inconstitucionalidad y fue publicada en el Boletín Oficial del Estado, núm. 294, de 4 de diciembre del 2017.

8 Publicado en el BOE del 27 de marzo del 2018, núm. 75.

${ }^{9} \mathrm{El}$ acuerdo publicado reza así: "[...] ha acordado: '1.Mantener la suspensión del art. 19.4 de la Ley del Parlamento de Cataluña 16/2017, de 1 de agosto, del Cambio Climático. 2. Levantar la suspensión del resto de preceptos impugnados'".

${ }^{10}$ Sobre esta sentencia véase también Marina Rodríguez Beas, donde analiza una parte de ella, "El conflicto competencial sobre cambio climático entre España y Cataluña: avances y retrocesos a la luz de la reciente Sentencia del Tribunal constitucional 87/2019, de 20 de junio, sobre la Ley 16/2017, de 1 de agosto, de cambio climático", A\&C, Revista de Direito Administrativo \& Constitucional, núm. 77, 2019 pp. 59-96, así como la crónica de Jordi Jaria Manzano "jurisprudencia constitucional en materia de protección del medio ambiente (segundo semestre 2019), RCDA Vol. X Núm. 2 (2019), en la que destaca el título "regresión y recentralización en materia de cambio climático: la sentencia sobre la ley catalana", pp. 2-12.
} 
En este trabajo vamos a abordar en qué situación queda la ley catalana de cambio climático tras esta sentencia, en la que se anulan varios preceptos importantes de la ley, lo cual puede hacer peligrar su aplicación y, por lo tanto, su finalidad, frenar el cambio climático. Estudiaremos la evolución normativa de esta misma ley tras esta STC.

\section{II. ¿CUÁL ES EL ESCENARIO ACTUAL?}

En 2020, tres años después de la promulgación de la LCCC, después de ese 2017 cuando se promulgó lo que fue la primera ley sobre cambio climático en el estado español, el escenario que la acompaña ha sufrido diversos cambios.

\section{La emergencia climática. Situación global}

Hoy en día la emergencia climática es aún más evidente. Los datos auguran un aumento de la temperatura mundial incluso mayor al inicialmente previsto, si no se toman cartas en el asunto de manera inmediata. Para 2100 parece que la temperatura podría aumentar hasta 4,5 grados centígrados! Además cada vez hay más desastres naturales más continuados y habituales, como por ejemplo el temporal Gloria que tuvo lugar en febrero de 2020. La era del antropoceno está en plena eclosión y es necesario revertirla también desde el ámbito jurídico. ${ }^{11} \mathrm{El}$ reto principal, reducir el aumento de la temperatura del planeta, debe ser tomado en serio para evitar las consecuencias que pueden acabar con nosotros o por lo menos, poner muy difícil nuestra supervivencia. Por otro lado, el nuevo escenario post-covid19 supone un nuevo reto para afrontar la emergencia climática.

\section{La situación en el ámbito internacional}

En el ámbito internacional la conferencia de cambio climático de las Naciones Unidas de 2020 (UNFCC COP 26), que debía celebrarse en Glasgow, ha sido aplazada al 2021, en motivo del COVID-19, a pesar de estar prevista su celebración para noviembre. Los distintos actores, preocupados por afrontar el cambio climático esperan que esto no suponga un freno para seguir trabajando en esta cuestión. En la última conferencia, la COP 25 Chile-Madrid los

11 Sobre el antropoceno véase, entre otros, Jordi Jaria Manzano, La constitución del Antropoceno, Tirant lo Blanch, 2020, Endrius Cocciolo, "La unión de la energía y la gobernanza del sistema tierra en el antropoceno: Una cuestión constitucional”, RCDA, vol. 6 núm.1, 2015 pp. 1-44. 
acuerdos que surgieron no fueron muy ambiciosos y mostraron que aún es necesario que haya cambios de raíz para poder afrontar esta crisis climática que estamos viviendo, a pesar de pedir a los países que aumenten su ambición en cuanto a perseguir los objetivos marcados por los Acuerdos de París. Esto propició a que fuera tildada de fracaso. Los Informes del IPCC ${ }^{12}$ siguen remarcando que es necesario limitar la temperatura media del planeta tierra a un aumento de 1,5 grados centígrados respecto a la época preindustrial, en su informe de octubre de 2018. Asimismo, se habla de adoptar un New Green Deal.

\section{La situación en el ámbito de la Unión europea}

En el ámbito europeo, Ursula Von der Leyen, encabezando la Comisión europea, aprobó a finales de 2019 la comunicación llamada "The European Green Deal"13, que incluye, entre otras cuestiones, la aprobación de la primera ley climática europea para marzo de 2020 a propuesta de la Comisión. ${ }^{14}$ Además pretende adoptar una nueva estrategia de adaptación al cambio climático más ambiciosa, e incidir en las políticas de producción de productos sostenibles para reducir de forma significativa los residuos. Asimismo, confía en las nuevas tecnologías, y apuesta por un sistema de alimentación más justo, saludable y ambientalmente sostenible. Se habla de la estrategia de la granja al tenedor, así como de prestar atención a la pérdida de biodiversidad, y a las áreas forestales, los océanos y los recursos acuáticos y marinos, conocidos como "blue economy". Se plantea también como propósito la

\footnotetext{
12 Para acceder a los informes véase https://www.ipcc.ch/languages-2/spanish/ [última consulta 20 de mayo de 2020].

${ }^{13}$ Communication from the commission to the european parliament, the european council, the council, the european economic and social committee and the committee of the regions, Bruselas, 11.12.2019 $\operatorname{COM}(2019) 640$ final

14 "This will enshrine the 2050 climate neutrality objective in legislation. The Climate Law will also ensure that all EU policies contribute to the climate neutrality objective and that all sectors play their part". Idem., p. 4. Existe una propuesta de Reglamento de 4 de marzo con dicho fin. Se trata de la propuesta de Reglamento del parlamento europeo y del consejo por el que se establece el marco para lograr la neutralidad climática y se modifica el reglamento (UE) 2018/1999 («ley del clima europea»), al que nos remitimos para mayor abundamiento. $\begin{array}{llllll}\text { Bruselas, } & 4.3 .2020 & \operatorname{COM}(2020) & 80 & \text { final. 2020/0036 } & \text { (COD) }\end{array}$ $<$ https://ec.europa.eu/transparency/regdoc/rep/1/2020/ES/COM-2020-80-F1-ES-MAIN-PART1.PDF >[Última consulta, 14 de abril de 2020].
} 
transición energética justa y la transición ecológica. Para ello se prevén medidas que comprende, entre otras, inversiones económicas. ${ }^{15}$

Este pacto ha sido bien acogido pero a la vez muy criticado. Se considera que a pesar de las buenas intenciones y de buscar la neutralidad del carbono para 2050 sigue priorizando el crecimiento económico ante todo. Esto conlleva tildarlo de "capitalismo verde", en donde todo cambia para no cambiar nada. Se critica, al fin y al cabo, que no se afronte un cambio sistémico que permita afrontar certeramente el gran reto del cambio climático sino que sea un mero "greenwashing". Las corrientes que defienden un cambio de modelo y que critican este pacto en este sentido son más ambiciosas con el cambio que requiere el mundo para realmente afrontar este reto climático. ${ }^{16}$

\section{La situación en el estado español}

En el estado español, existen varias iniciativas legislativas destinadas a afrontar el cambio climático. Hay más Comunidades autónomas (en adelante, CCAA) que han aprobado sus respectivas leyes de cambio climático, además de Catalunya - en Andalucía, la ley $8 / 2018$, de 8 de octubre, de medidas frente al cambio climático para la transición hacia un modelo nuevo energético y en Islas Baleares, la ley 10/2019, de cambio climático y transición energética - y otras que están en tramitación - Región de Murcia, Navarra, País Vasco -. En el ámbito estatal, por el momento, y a pesar del compromiso de promulgar la ley de cambio climático dentro de los siguientes cien días del nuevo gobierno, tras las elecciones, sigue estando en espera la aprobación de ley de cambio climático. Es cierto también que la situación actual de estado de alarma, por el

\footnotetext{
15 Sobre este pacto véase Dionisio Fernández de Gatta "El ambicioso pacto verde europeo", en Actualidad Jurídica Ambiental, núm. 101, sección comentarios, de 12 de mayo de 2020. ISSN: 1989-5666; NIPO: 832-20-001-3.

${ }^{16}$ Entre los autores que defienden este cambio sistémico se encuentra Jorge Riechmann, quien como filósofo más ha ahondado en esta cuestión, así como Yayo Herrero. Por ejemplo, en relación con las cuestiones que tiene que cambiar se encuentra el modo de contabilizar la riqueza de un país. El autor, entre otros, propone superar el PIB e introducir cuestiones como el impacto del cambio climático en el método de cálculo en "Calentamiento climático. ¿Cómo se calcula su impacto?", en Nuria del Viso (coord.) Cambio climático: un reto social inminente, fuhem, Madrid, 2005. Un cuestionamiento al actual sistema para afrontar la crisis ecológica lo encontramos en "la crítica ecosocialista al capitalismo", Revista Integra Educativa, v.6 La paz, dic. 2013.
} 
COVID-19 y de confinamiento, han propiciado que se atrase. No obstante, parece que verá la luz próximamente. ${ }^{17}$

Se han promulgado numerosas declaraciones de emergencia climática a nivel local, autonómico, estatal, e internacional, que advierten que es necesario tomar parte en este asunto, para revertir las consecuencias devastadoras que el cambio climático tendrá sobre el planeta y en especial sobre la especie humana.

\section{La situación en Catalunya}

El Gobierno de Catalunya aprobó el 14 de mayo de 2019 la Declaración de Emergencia Climática. ${ }^{18}$ Además tiene aprobado el Plan Nacional para la Agenda 2030 para logar los Objetivos de Desarrollo Sostenible. ${ }^{19}$

\footnotetext{
${ }^{17}$ En la fecha de cierre de esta publicación se ha iniciado la tramitación parlamentaria del primer Proyecto de Ley de Cambio Climático y Transición Energética en el Congreso de los Diputados España (en adelante, PLCCTE).

${ }^{18}$ De la que se derivan numerosos compromisos: "Adoptar las medidas de simplificación administrativa necesarias para eliminar los obstáculos que puedan poner en peligro la consecución de los objetivos en materia de mitigación del cambio climático y transición energética; Incrementar los incentivos y priorizar las políticas y los recursos públicos destinados a la necesaria transición hacia un modelo energético cien por cien renovable, desnuclearizado y descarbonizado, neutro en emisiones de gases de efecto invernadero, que reduzca la vulnerabilidad del sistema energético catalán y garantice el derecho al acceso a la energía como bien común, como fija la Ley 16/2017, del cambio climático; Priorizar, en las políticas públicas, las opciones con menor impacto climático y mayor contribución a la adaptación a las condiciones derivadas del cambio climático; Adoptar las medidas necesarias para parar la preocupante pérdida de biodiversidad y promover la recuperación de los ecosistemas; Identificar y acompañar los sectores de la economía que tienen que hacer una transición, sea para adaptarse a las nuevas condiciones derivadas del cambio climático, sea para transformarse en actividades de bajas emisiones de gases de efecto invernadero (GEI), en un marco general de apuesta por la economía circular y de creación de puestos de trabajo verdes; Adoptar las medidas encaminadas a reducir la vulnerabilidad de aquellos sectores sociales más sensibles a los impactos del cambio climático y a aquellos otros a los cuales esta transición puede afectar en mayor grado; Asumir un modelo de movilidad urbana basado, por una parte, en el transporte público, en el vehículo compartido y en los modos de micromovilidad y, por otra, en vehículos de emisión cero; Declarar instalaciones de interés territorial estratégico las instalaciones fotovoltaicas que utilicen sistemas de captación de energía fotovoltaica avanzados y eficientes; Elaborar, conjuntamente entre el Departamento de Territorio y Sostenibilidad y el Departamento de Empresa y Conocimiento, una estrategia territorial para la implantación de las instalaciones de energía renovable, fundamentalmente eólica y fotovoltaica, necesarias para desarrollar la transición energética en Cataluña y cumplir con los objetivos de la Ley 16/2017, del cambio climático, en materia de energía; Instar al Parlamento a celebrar cada año un pleno monográfico sobre el cambio climático y su afectación en Cataluña y sobre las medidas de mitigación y adaptación que el Gobierno adopte, en especial las asociadas a la transición energética; Revisar la legislación catalana vigente con la finalidad de detectar aquellas normas que favorezcan la emisión de gases de efecto invernadero o dificulten combatir los efectos del cambio climático." Cabrá ver en qué medida se cumplen.

$19<$ http://cads.gencat.cat/ca/Agenda 2030/pla-nacional/> [última consulta, 14 de abril de 2020].
} 
En el marco de este escenario es donde se sitúa la actual LCCC, que una vez pasada por la tijera del Tribunal Constitucional ha quedado mutilada y, por lo tanto, aparentemente, con alguna que otra dificultad para poder ser desplegada de forma efectiva y lograr los retos que se planteaba inicialmente. Sin embargo, Catalunya no se ha quedado de brazos cruzados y, para atender la emergencia climática ha promulgado normativa que desarrolla esta ley, como ya tenía previsto $^{20}$, en aquellos ámbitos que ha quedado salvada su constitucionalidad, y ha dictado normativa que suple, complementa y redefine las cuestiones afectadas por la STC. La Generalitat de Catalunya ha aprobado por primera vez un plan normativo de los años 2019-2020, el cual incluye varias normativas que suponen un desarrollo de la ley 16/2017 de forma directa o que tienen relación con la mitigación y adaptación del cambio climático, por afectar a las políticas sectoriales que se ven implicadas. ${ }^{21}$ Sin embargo muchas de ellas aún están en tramitación.

Destaca, entre esta normativa, el Decreto Ley 16/2019, de 26 de noviembre, de medidas urgentes para la emergencia climática y el impulso a las energías renovables que, entre otros, modifica algunos artículos de la LCCC. Se ha promulgado el Decreto 33/2020 que desarrolla la Comisión Interdepartamental de Cambio Climático y el Fondo Climático y la Ley 9/2019, que ha modificado artículos de la LCCC que afectan al impuesto sobre vehículos de tracción mecánica. Además se han iniciado los trámites para desarrollar otros aspectos que incluye la ley, como son los otros dos impuestos que crea la LCCC - el impuesto sobre las emisiones portuarias de grandes barcos y el impuesto sobre las actividades económicas que generan gases con efecto invernadero -. Asimismo, se ha sometido a consulta pública previa la propuesta de Anteproyecto de ley de prevención y gestión de residuos y del uso eficiente de los recursos de Catalunya, entre otras acciones.

\footnotetext{
${ }^{20}$ Entre las medidas legislativas a adoptar en el Plan de Gobierno aprobado para la XII legislatura, el 2018 se encuentra la del desarrollo reglamentario de la ley 16/2017, entre otras. Se incluye en el segundo eje programático de las prioridades de acción en la lucha contra el cambio climático, dedicado a "una economía próspera, responsable y sostenible. Para un nuevo modelo productivo y una fiscalidad justa" <https://web.gencat.cat/es/actualitat/detall/20180925_Pla-de-Govern-XII-legislatura> [última consulta, 14 de abril de 2020].

${ }^{21}<$ https://presidencia.gencat.cat/web/.content/ambits actuacio/millora regulacio normativa/Pla -normatiu/Pla-normatiu-2019-2020-diligenciat.pdf > [última consulta, 14 de abril de 2020].
} 
El Decreto Ley 16/2019, de 26 de noviembre, de medidas urgentes para la emergencia climática y el impulso a las energías renovables tiene por voluntad, como indica su exposición de motivos, acelerar el proceso de desarrollo de los instrumentos de la LCCC, con el fin de hacer frente a la emergencia climática, por lo que adopta medidas urgentes para dicho enfrentamiento. Sin embargo, a la vista de las cuestiones que regula, es criticable que se haya optado por esta figura, ya que comporta que se evite todo debate en sede parlamentaria y la participación pública.

El objeto de la este decreto ley se concreta en tres cuestiones básicas. En primer lugar, "adoptar medidas urgentes para hacer frente a la situación de emergencia climática mediante una transición ecológica y energética que permita alcanzar en el más breve plazo posible los objetivos fijados en la Ley 16/2017, del 1 de agosto, del cambio climático." En segundo lugar, "modificar el Texto refundido de la Ley de urbanismo, aprobado por el Decreto legislativo 1/2010, de 3 de agosto, para facilitar y simplificar la implantación de las instalaciones para el aprovechamiento de la energía solar y eólica y, en tercer lugar "determinar los requisitos para la autorización de las instalaciones de producción de energía eólica y de energía solar fotovoltaica; definir los criterios energéticos, ambientales, urbanísticos y paisajísticos que deben regir su implantación, y simplificar el procedimiento administrativo aplicable para su autorización" (art. 1).

En relación con el primer objeto del decreto ley vemos que la urgencia viene marcada por la necesidad de adaptar los artículos revisados por parte del TC para poder aplicar la ley y desplegarla en su totalidad.. Los otros dos objetivos, tiene como fin facilitar la implantación de instalaciones de energía eólica y solar fotovoltaica.

En definitiva, la emergencia climática es un hecho y es necesario que todas las instancias y todos los actores tomemos medidas para revertir la situación. Sin embargo, como veremos, la interpretación de los títulos competenciales implicados en materia de cambio climático no permite que esta protección se ejerza de forma efectiva por todos los actores implicados. La atención sobre el desarrollo económico provoca que la protección medioambiental esté siendo 
mermada y esté sufriendo un grave retroceso, lo que perjudica y agrava la situación actual que precisamente requiere la acción contraria.

\section{EL DEBATE COMPETENCIAL EN RELACIÓN CON EL CAMBIO CLIMÁTICO. LA RECENTRALIZACIÓN DE COMPETENCIAS.}

El sistema competencial español es un sistema muy fragmentado con el reconocimiento de numerosos títulos competenciales que confluyen en materia de cambio climático. El cambio climático como tal no está reconocido ni como objeto de protección en sí mismo por la CE ni por ningún título competencial concreto. El título competencial de protección de medio ambiente recoge esta cuestión, de forma sustancial pero no es el único título que se ve implicado en esta materia, puesto que afecta a muchos otros ámbitos, como es el ámbito energético, por ejemplo. De hecho, el cambio climático tiene una afectación global y como tal debería ser abordada de forma holística y global. Sin embargo esta visión global no encaja en el sistema actual constitucional, y menos en la interpretación que últimamente está adoptando la jurisprudencia cuando se trata de regular cuestiones relacionadas con el cambio climático. El título competencial de protección ambiental es el que más lo sustenta pero es cierto que entran en juego otros títulos que también deben tenerse en cuenta.

Todas las leyes autonómicas estatales vigentes y en tramitación, cuya finalidad es la mitigación y adaptación del cambio climático, tienen un carácter sustancialmente ambiental, por lo que están amparadas por el título competencial de protección del medio ambiente que establece el artículo 149.1.23 CE. Este título reserva la legislación básica de la protección del medio ambiente al Estado, al que le corresponde la ordenación mediante mínimos de dicha protección. Su desarrollo y ejecución queda en manos de las CCAA, a las que también les otorga la potestad de dictar normas adicionales de protección. Por ello, asumen un elevado nivel competencial en materia ambiental. Catalunya, concretamente, acoge dicha competencia de protección del medio ambiente como exclusiva en el artículo 144 de su Estatuto de Autonomía. Esta incluye las cuestiones relativas al cambio climático. Asimismo, entra en conexión con otras materias, como son el turismo, la ordenación del territorio y la vivienda, entre otras. 
Sin embargo, y así lo recalca el Recurso de inconstitucionalidad contra la ley catalana de cambio climático, este no es el único título competencial que concurre sino que cobran protagonismo otros dos títulos competenciales, en los que se va a apoyar el recurso, principalmente, para argumentar que Catalunya se está extralimitando en el ejercicio de sus competencias. Se trata del artículo 149.1.13 CE, que otorga al Estado la competencia exclusiva sobre las bases y coordinación de planificación general de la actividad económica y el artículo 149.1.25 CE, que reserva las bases del régimen minero y energético al Estado. Estos títulos habilitan al Estado para aquellas normas que regulen $u$ ordenen de manera directa dicha economía general y el régimen minero y energético. No obstante, existen discrepancias sobre el alcance de estas competencias y de su ejercicio. Asimismo, también se hace valer el propio artículo 149.1.23 CE en cuanto a la falta de legislación básica estatal sobre protección del medio ambiente en aspectos que regula Catalunya de forma novedosa. Como veremos estos tres títulos competenciales van a servir de fundamento en la STC 87/2019 para declarar la nulidad de muchos de los artículos que se impugnan de la LCCC.

En definitiva, el recurso de inconstitucionalidad que se interpuso es estrictamente competencial. Se alegó que la Ley catalana invadía las competencias exclusivas del Estado en materia de bases y coordinación de la planificación general de la actividad económica, legislación básica sobre protección del medio ambiente y bases del régimen minero y energético (apartados 13, 23 y 25 del artículo 149.1 de la CE), a estos títulos se le suman las competencias en materia de hacienda general y de puertos de interés general (apartados 14 y 20 del artículo 149.1 de la CE). Además, se consideró que había una dimensión de la Ley que permitía considerarla como creadora de una estructura de Estado, en la práctica, ajena a cualquier vinculación con las políticas y el marco jurídico del Estado, al prescindir por completo de las competencias estatales exclusivas.

Es cierto, que la ley catalana en ningún momento se refiere de forma expresa a la normativa básica estatal y que su Estatuto de Autonomía no comprende un título específico para la ejecución del derecho de la UE, sin embargo, todo ello se puede deducir del propio ordenamiento jurídico y de su configuración. 
Sorprende que la ley $8 / 2008$, de 8 de octubre, de medidas frente al cambio climático y para la transición hacia un nuevo modelo energético en Andalucía y la Ley balear 10/2019, de 22 de febrero, de cambio climático y transición energética, en cambio, no han sido objeto de recurso, a pesar de regular cuestiones muy similares o idénticas e incluso mucho más ambiciosas y arriesgadas que la ley catalana. Sin embargo, como hecho diferencial, en ambos casos sí que se ha hecho referencia expresa a la legislación básica estatal, en especial, a la relativa a la protección del medio ambiente. Además el Estatuto de Autonomía de las Illes Balears reconoce expresamente que puede transponer directamente el derecho de la UE. No obstante, la ley balear no está exenta de dudas constitucionales para el Estado y por ello ha creado una Comisión bilateral Estado-Comunidad autónoma para tratar estos aspectos.

Ceñir el debate a esta cuestión tan formal cuando la situación del cambio climático es tan compleja comporta que en la práctica se esté desprotegiendo y cercenando competencias de las autonomías, como actores importantes para frenar el cambio climático.

Como veremos durante el trabajo la STC 87/2019, es una muestra más de la recentralización de competencias a favor del Estado y en detrimento de las Comunidades autonómicas, en las que prevalece el desarrollo económico frente a la protección ambiental. Esto supone a su vez una regresión en la propia protección ambiental. La tensión entre protección del medio ambiente y desarrollo económico, acaba resolviéndose a favor del desarrollo económico, dando más protagonismo a esta competencia que a la de protección del medio ambiente. Así se ha visto desde la crisis de 2008 en las sucesivas sentencias del TC en las que ha priorizado el artículo 40 al 45 de la Constitución española. La línea jurisprudencial desarrollada por el TC en los últimos años ha promovido un recorte de competencias autonómicas en materia de protección ambiental a favor de unas competencias estatales fundamentadas principalmente en cuestiones económicas. Esta interpretación también ha llegado al cambio climático. En este sentido el TC banaliza la situación actual en la que se encuentra el planeta y adopta una interpretación formal que impide que las CCAA puedan ejercer sus competencias en este ámbito. Esta tendencia a la recentralización ha sido constatada por autoras como CASADO 
CASADO que de forma exhaustiva analiza la evolución del derecho ambiental en los últimos años en relación con esta cuestión. ${ }^{22}$

\section{IV. ¿CUÁLES SON LAS PRINCIPALES CUESTIONES DE LA LCCC DE LAS QUE SE DUDA DE SU CONSTITUCIONALIDAD? ¿CÓMO SE RESUELVEN?}

A continuación vamos a analizar de forma minuciosa aquellas cuestiones de la LCCC que han sido puestas bajo sospecha de constitucionalidad. Vamos a centrarnos únicamente en las cuestiones que han sido impugnadas y, por ello, en relación con la globalidad de la ley, nos remitimos a otros trabajos elaborados previamente. En este capítulo queremos destacar, manteniendo el orden y estructura de la ley, por materias, los artículos impugnados, ver cómo se han resuelto por parte del TC y cuál ha sido la respuesta por parte del Govern de la Generalitat de Catalunya y del Parlament para dar aplicación a su contenido, incluso tras la reducción de competencias sobre cambio climático a las que ha sido sometida de facto la LCCC con la aplicación de la STC $87 / 2019$.

\section{La mitigación del cambio climático: los objetivos y las herramientas} para su logro

El recurso de inconstitucionalidad, como ya hemos avanzado anteriormente, impugnó numerosos artículos de la LCCC y cuestionó la legalidad de cuestiones importantes de la ley, cuya anulación puede tener un impacto significativo en su aplicación. En primer lugar, en el ámbito de la mitigación del cambio climático este recurso considera inconstitucionales cuestiones tan relevantes como los objetivos de reducción de los GEI (art.5), el marco estratégico de referencia de mitigación (art.6), los presupuestos del carbono (art.7) y el inventario de emisiones a la atmósfera y de sumideros de $\mathrm{CO} 2$ de Catalunya (art.8), además de las Disposiciones Adicionales que desarrollan estos artículos. Es decir, casi la totalidad del capítulo I de la ley. Veamos qué

\footnotetext{
${ }^{22}$ Lucía Casado Casado, La recentralización de competencias en materia de protección del medio ambiente, Generalitat de Catalunya, Institut d'Estudis de l'Autogovern, 2018.
} 
ha sucedido en cada ámbito cuestionado y a qué conclusiones llega el TC al respecto.

Tanto el Marco Estratégico de Referencia de mitigación como el Inventario de emisiones a la atmósfera han sido considerados constitucionales por parte del TC tras el análisis de los motivos alegados, ya que se considera que no contradicen la legislación del Estado. En cambio, tanto los presupuestos del carbono como los objetivos de reducción de los GEI, tal y como están establecidos en la LCCC, se considera que el Parlament de Catalunya se está extralimitando en sus competencias legislativas en algunos aspectos.

\section{a) Los presupuestos del carbono}

Los presupuestos del carbono, regulados en el artículo 7 de la ley, se divide en 4 apartados $^{23}$ y en la Disposición Transitoria sexta que desarrolla cuestiones concretas de calendario. ${ }^{24}$ Se trata de una herramienta novedosa que en el ordenamiento jurídico español no se ha usado por el momento, pero en cambio sí que tiene su aplicabilidad en otros estados, como Reino Unido.

El recurso de inconstitucionalidad considera que este instrumento es contrario a la constitución, en especial a los artículos que ya hemos hecho referencia con anterioridad, el 149.1.13 CE, 149.1.23 CE y 149.1.25 CE, poniendo especial énfasis en el artículo 149.1.13.

La STC 87/2019, una vez realizado el correspondiente análisis, llega a la conclusión de que no es contrario a derecho fijar una cuota alícuota pero, en

\footnotetext{
${ }^{23}$ Este artículo reza del siguiente modo " 1 . Los presupuestos de carbono, como mecanismo de planificación y seguimiento para la integración de los objetivos de la presente ley en las políticas sectoriales, deben concretarse de acuerdo con el artículo 5. Se establecen por períodos de cinco años y se aprueban con una antelación de diez años.

2. Corresponde al Parlamento aprobar los presupuestos de carbono, a propuesta del Gobierno, en base a las recomendaciones del Comité de Expertos sobre el Cambio Climático y previa presentación a la Mesa Social del Cambio Climático.

3. Los presupuestos de carbono, además de la cantidad total de emisiones permitidas para el conjunto de Cataluña, deben indicar qué parte corresponde a los sectores cubiertos por un sistema de comercio de derechos de emisión, en conjunto, y qué parte corresponde a sectores no cubiertos por ese sistema, también en conjunto.

4. Para establecer cada presupuesto de carbono, deben tenerse en cuenta, entre otros factores, el conocimiento científico, los impactos sobre los diferentes sectores y los potenciales de reducción de cada uno, las circunstancias económicas y sociales, la competitividad, la política energética, los escenarios de emisiones y los nuevos tratados internacionales."

${ }^{24}$ El calendario que se concreta en la ley es el siguiente: para los períodos 2021-2025 y 20262030 deben aprobarse como máximo el 31 de diciembre de 2020 y para el período 2031-2035 como máximo el 31 de diciembre de 2023. Sin embargo no se ha aprobado ninguno de ellos.
} 
cambio, sí que considera que se están invadiendo competencias estatales cuando se territorializa y se concretan dichas cuotas. En palabras del TC "no hay ninguna ley que prevea que los poderes públicos pueden fijar un límite máximo de emisiones para el conjunto de actividades contaminantes que se desarrollen en su territorio, sea para el conjunto de España o el de cada nacionalidad o regiones" pero la LCCC sí que permite prohibir emisiones por encima de una determinada cantidad total "presupuestada". La STC considera que hay una contradicción efectiva e insalvable con el carácter formal básico de los preceptos estatales, por lo que considera que, a pesar de salvar las cuestiones generales que plantea la ley en relación con los presupuestos del carbono, en su artículo 7, el apartado 3 debe ser declarado inconstitucional.

Este artículo indica que "los presupuestos de carbono, además de la cantidad total de emisiones permitidas para el conjunto de Cataluña, deben indicar qué parte corresponde a los sectores cubiertos por un sistema de comercio de derechos de emisión, en conjunto, y qué parte corresponde a sectores no cubiertos por ese sistema, también en conjunto". La incompatibilidad se encuentra en la territorialización unilateral de derechos de emisión por parte de Catalunya. Si una actividad tiene autorizadas ciertas emisiones de acuerdo con la ley estatal, la Ley 1/2005, de 9 de marzo, por la que se regula el régimen del comercio de derechos de emisión de gases de efecto invernadero, el TC considera que una Comunidad autónoma no puede limitar estas emisiones en su territorio. La ley catalana habilita a la Comunidad autónoma para prohibir emisiones por encima de una cantidad "presupuestada" y "permitida" por ella. De este modo se considera que se está contradiciendo el derecho estatal, ya que debe estar sometido a él. Todo ello se fundamenta en la competencia 149.1.13 CE que recordemos que reserva al Estado las bases y coordinación de la planificación general de la actividad económica.

Como avanzábamos esta interpretación formalista impide que se lleva a cabo una medida efectiva para revertir el cambio climático.

En la actualidad y tras esta sentencia, en cuanto a los presupuestos del carbono, que vieron alterada su regulación en relación con la indicación de qué parte corresponde a los sectores cubiertos por un sistema de comercio de derechos de emisión, en conjunto, y qué parte corresponde a sectores no 
cubiertos por ese sistema, el Decreto Ley 16/2019 ha añadido un nuevo apartado: "los presupuestos de carbono tienen que incluir las contribuciones de cada uno de los sectores, de acuerdo con la contabilidad de los inventarios de emisiones a la atmósfera y de evacuadores de $\mathrm{CO}_{2}$." Como vemos, se trata de una redacción que se refiere de forma más genérica a las mismas cuestiones que pretendía el redactado inicial anulado. En esta ocasión toma como referencia la contabilidad de los inventarios de emisiones a la atmósfera y de evacuadores de $\mathrm{CO}_{2}$.

En conclusión, a pesar de verse afectado por la STC 87/2019, se ha establecido una nueva redacción que pretende suplir las carencias que implicaban la anulación del apartado 3, quedando en vigencia el instrumento, en los términos expuestos.

\section{b) Los objetivos de reducción de emisión de GEI}

El artículo 5 y la Disposición Adicional primera de la LCCC regulan los objetivos de reducción de las emisiones de GEI, los cuales han sido también sometidos al correspondiente análisis por parte del TC. La LCCC, ajustándose a los compromisos adoptados en el Acuerdo de París y asumidos por la UE y por el estado español - además de prever la presentación de los objetivos de reducción de emisión de GEl por parte del Gobierno al Parlamento para que los apruebe, para los períodos de cumplimiento que establezcan la Unión Europea y la Organización Mundial de la Salud y fijar la periodicidad de cinco años, entre otras cuestiones - fija una hoja de ruta para lograr la reducción de los GEI, de forma escalonada y ambiciosa. Es decir, concreta el íter y los objetivos a lograr para cada periodo.

En primer lugar, prevé una reducción del $40 \%$ de los GEI para el 2030, tomando como referencia el año 1990; del 65\% para el año 240 y del $100 \%$ para el 2050, logrando así la neutralidad comprometida. Además fija otros objetivos de reducción, de óxido de nitrógeno, en un 35\% para el 2020 y de partículas en suspensión de menos de 10 micras, en un 30\%. Asimismo, los objetivos de reducción de GEI para las energías renovables en producción energética y para la eficiencia energética se establecen en el $100 \%$ con el horizonte de un modelo neutro de emisiones de carbono para el 2050. Con este fin habilita al departamento competente en materia de medio ambiente 
para que establezca "objetivos concretos, sectoriales, de regulación vinculante y con indicadores anuales para períodos de cinco años, teniendo en cuenta los sectores que tienen más potencial de reducción de emisiones con menores costes económicos y basándose en su política de transición energética, con la redacción del correspondiente plan de transición energética, y en lo establecido por la presente ley."

Toda la concreción a la que nos hemos referido en el párrafo anterior y la hoja de ruta establecida por la ley catalana, tras la revisión constitucional, han sido anuladas. El calendario de reducción de emisiones de GEl entre otras se ha esfumado. No existe un camino concreto de objetivos para lograr mitigar el cambio climático. La STC anula la Disposición Adicional primera que regula los objetivos de reducción de GEI.

En primer lugar, y tras el análisis del apartado 3 de esta Disposición Adicional que prevé los objetivos de reducción de las emisiones en el ámbito de la energía, el TC entiende que se vulneran las bases estatales que reconocen el derecho de los productores de energías a usar las fuentes que consideren más adecuadas. Este apartado fija los objetivos de reducción de gases de efecto invernadero para las energías renovables en la producción energética y para la eficiencia energética en el $100 \%$ con el horizonte de un modelo neutro en emisiones de carbono para 2050. En cambio considera que los apartados 1,2 y 4 tienen un alcance general y no se ciñen al ámbito de la energía. Sin embargo, deben seguir la misma suerte y anularse porque vulneran la legislación básica del Estado sobre emisiones contaminantes en los mismos términos que el artículo 7.3 - comentado en el apartado anterior - ya que señalan directamente objetivos vinculantes, concretos, mensurables y a término de reducción de emisiones contaminantes que son inconciliables con la posibilidad y el derecho a emitir GEI reconocidos por el Estado en la ya citada Ley $1 / 2005$ y también en la Ley 34/2007, de 15 de noviembre, de calidad del aire y protección de la atmósfera y en el Real Decreto Legislativo 1/2016, de 16 de diciembre, por el que se aprueba el texto refundido de la Ley de prevención y control integrados de la contaminación.

Por lo tanto, aunque la STC conserva la redacción del artículo 5 en tanto que se refiere a los objetivos de reducción de GEI de forma genérica, anula la 
Disposición Adicional primera que detalla los objetivos de reducción de GEl. En conexión con esta cuestión anula también el artículo 19.6 primer inciso en lo que se refiere expresamente a esos objetivos al disponer que la planificación energética debe incorporar los objetivos de reducción de emisiones establecidos en la ley. Lógicamente si estos objetivos quedan anulados todo aquello que se refiera a ellos de forma expresa deben quedar anulados también, como es el caso de este inciso de este artículo, al que volveremos posteriormente, cuando tratemos cuestiones que afectan a la energía de forma estricta.

En resumen, se puede afirmar que los objetivos genéricos se consideran constitucionales mientras que los concretos no. Por lo tanto, establecer como objetivo la transición energética o la reducción de las emisiones de GEI se considera constitucional pero concretar como se va a lograr, fijando objetivos concretos no, ya que se interpreta que esa cuestión debe quedar en manos exclusivas del estado. En todos estos supuestos más concretos se considera que Catalunya se está extralimitando de sus competencias, principalmente amparándose en que esta concreción de los objetivos debe establecerla la ley básica estatal. Esta interpretación supone una nueva merma de las competencias autonómicas y una recentralización en manos del Estado de estas cuestiones que comporta a su vez una regresión en la protección ambiental y, en definitiva, en el objetivo de lograr una mitigación del cambio climático.

La anulación de todas las cuestiones que suponían una concreción en relación con los objetivos de reducción de los GEI para la mitigación del cambio climático conllevan que la ley quede huérfana de los mismos, puesto que más allá de las indicaciones de los Acuerdos de París y de la UE no existe a día de hoy en España como conjunto unos objetivos establecidos. Recordemos que, en cambio, aquellas cuestiones que se refieren a dichos objetivos de forma genérica se consideraron acordes a la constitución.

En este ámbito nos preguntamos, ¿si hubiera ley estatal básica aprobada podría, en base a las normas adicionales de protección en materia ambiental, establecer estos objetivos más ambiciosos, cómo lo han hecho Andalucía y Baleares sin oposición alguna? ¿Cuando se apruebe el hoy PLCCTE que 
prevé un objetivo del $20 \%$ para el 2030 en contraposición a los objetivos más ambiciosos de Baleares y Andalucía que estarán amparados por este título del artículo 149.1.23 CE y la posibilidad de dictar normas adicionales de protección? Para nosotros la decisión constitucional no tiene ningún sentido y comporta una desprotección ambiental.

Tras la revisión constitucional que deja intacto este artículo 5, pero que anula la Disposición Adicional primera en la que se desarrollaba y se concretaban estos objetivos el legislador catalán ha optado por incorporar un apartado tercero al mencionado artículo 5 a través del Decreto Ley 16/2019 y que reza del siguiente modo: "Los objetivos en materia de reducción de emisiones de gases de efecto invernadero a los que se hace referencia en los apartados anteriores tienen que ser congruentes con un escenario neutro en emisiones de gases de efecto invernadero a largo plazo en el marco de la visión estratégica europea." Con ello, se recuerda la necesidad de lograr a largo plazo un escenario neutro de emisiones de GEI teniendo en cuenta las directrices de la UE. Como vemos se alinea con el European Green Deal y, entendemos que con lo que será la próxima ley climática europea que persigue dicho objetivo. Se desprende del mismo la ambición de que estos objetivos tengan como fin un escenario neutro de emisiones de GEI a largo plazo teniendo en cuenta la visión de la UE al respecto. Se recuerda esta voluntad. Sin embargo, sigue faltando una concreción del calendario en el que se fije la hoja de ruta para lograr dicho fin, la neutralidad de emisiones. ${ }^{25}$

Por lo tanto, en vez de propiciar que los actores llamados a revertir el cambio climático, como lo son también las CCAA, puedan regular sobre la mitigación estableciendo un calendario con objetivos ambiciosos acordes con la UE y los acuerdos de París, la interpretación jurisprudencial solo hace que poner freno a este avance anclándose en la interpretación recentralizadora de competencias a favor del Estado. Aunque como vemos tan solo se ha visto esta problemática competencial con Catalunya, ya que Baleares y Andalucía tienen vigente su hoja de ruta plasmada en sus normas autonómicas de cambio climático. Esta cuestión tampoco se entiende.

${ }^{25}$ PLCCTE estatal fija en un $20 \%$ la reducción de emisiones de GEI para 2030 respecto a 1990 y pretende alcanzar la neutralidad para 2050. A pesar de que se tilde de ambicioso es la mitad del porcentaje que pretendía asumir Catalunya (40\%), para el mismo año. 


\section{La adaptación al cambio climático: la planificación puesta en duda}

Catalunya dispone desde el año 2012 de la estrategia catalana de adaptación al cambio climático con el horizonte 2013-2020, conocida como ESCACC, aprobada por acuerdo de Gobierno del 13 de noviembre de 2012. Esta fue incluida en la LCCC como marco estratégico para lograr la adaptación al cambio climático. A pesar de estar vigente y en aplicación durante todos estos años ha sido puesta en entredicho por el Recurso de Inconstitucionalidad. El motivo ha sido que incluye "las modificaciones pertinentes derivadas de los acuerdos internacionales que vayan produciéndose, de acuerdo con los artículos $10.1^{26}, 28.1^{27}$ y $28.2^{28}$, el elemento de planificación de las políticas de adaptación a partir del cual los departamentos de la Generalitat, en el ámbito de sus respectivas competencias, deben desarrollar los planes de acción sectoriales correspondientes de acuerdo con el artículo 10.3" (DA3). Sin embargo una vez analizados los motivos de la impugnación por parte del TC se considera que dicho Plan es totalmente conforme a la constitución y, por lo tanto, sigue vigente, tanto el plan como las modificaciones que se puedan introducir en los términos que apunta.

En el marco de la adaptación al cambio climático no ha sido el único instrumento que ha sido objeto de impugnación sino que se cuestionan, además de los artículos que regulan el marco estratégico de referencia de adaptación y los instrumentos de planificación y programación, algunos aspectos relacionados con la regulación de las políticas sectoriales para la adaptación al cambio climático. Trataremos a continuación estas cuestiones de forma detallada.

\footnotetext{
${ }^{26}$ Relativo a que el marco estratégico de referencia de adaptación debe recoger: a) La evaluación de los impactos, de acuerdo con el estado del conocimiento; b) La identificación de los sistemas naturales, de los territorios y de los sectores socioeconómicos más vulnerables; c) Una propuesta de las medidas de adaptación necesarias para reducir la vulnerabilidad.

27 Donde se establece que la planificación de las políticas climáticas debe incluir la mitigación de gases de efecto invernadero de todos los sectores generadores y la adaptación a los impactos del cambio climático sobre los sistemas naturales, los sectores socioeconómicos y los territorios. Dicha planificación debe establecer los objetivos y las medidas genéricas, que deben incluir, necesariamente y como mínimo, las establecidas por el capítulo tercero.

${ }^{28}$ Se prevé que se establezcan periódicamente objetivos relativos al porcentaje mínimo de consumo de energía de origen renovable en las instalaciones públicas que sean propiedad de la Generalidad y de las entidades de su sector público y en aquellas en las que figuren como arrendatarios, siempre y cuando las condiciones contractuales permitan el cumplimiento de estos objetivos y su gestión sea competencia de los departamentos de la Generalidad y de las entidades de su sector público.
} 


\section{Las políticas sectoriales}

a) Las aguas

El artículo 16 de la LCCC regula las cuestiones relativas a las aguas en el ámbito del cambio climático y dedica su apartado tercero a tratar la interconexión de redes de abastecimiento.

Este apartado tercero se plantea como inconstitucional, en aquello relacionado a la cuestión relativa a las medidas encaminadas a reducir la vulnerabilidad del sistema hídrico en lo que se refiere a las interconexiones de las redes de abastecimiento, cuando afecte a cuencas hídricas.

La premisa del TC y, en base al principio de conservación de la ley, es derogar tan solo aquellos artículos cuya incompatibilidad con la Constitución resulte indudable por ser imposible llevar a cabo una interpretación que la haga caber. En esta ocasión, el artículo art. 16.3 sobre cuencas intracomunitarias e intercomunitarias impugnado permite una interpretación que evite la derogación del artículo, entendiendo que la referencia a la cuencas hídricas es exclusiva de las intracomuntarias, es decir, a aquellas que transcurren por la propia comunidad autónoma. Se interpreta que cuando se refiere a las "cuencas hídricas" lo hace tan solo a las de competencia de la Generalitat, esto es las intracomunitarias, por lo que la STC decide conservar este artículo, tal y como esta redactado.

b) La transición energética: objetivos, planificación y medios cuestionados

Una de las cuestiones más relevantes que ha sido impugnada de la LCCC es la relacionada con la transición energética. Se trata además de cuestiones estratégicas que persiguen una transformación del modelo energético que prima en la actualidad, un modelo energético obsoleto que requiere de un cambio. Cambio que se resiste tras la interpretación jurisprudencial acaecida, como veremos.

El artículo 19 de la LCCC, que consta de seis apartados, es el que centra la regulación de las cuestiones relacionadas con la energía para lograr los objetivos que se plantean. Este artículo promueve la transición energética hacia un modelo cien por cien renovable, desnuclearizado y descarbonizado, neutro en emisiones de gases de efecto invernadero, que reduzca la 
vulnerabilidad del sistema energético catalán y garantice el derecho al acceso a la energía como bien común. Para ello se plantea unos objetivos y unas acciones muy concretas, arriesgadas y ambiciosas que, una vez más son llevadas ante el TC por entender que estas medidas exceden de la competencia que pueden ejercer las CCAA en este ámbito. Veamos con detenimiento qué regula el artículo 19, qué cuestiones quedan anuladas, cuáles perviven tras el filtro de constitucionalidad y qué normativa ha desarrollado estas cuestiones con posterioridad.

Para lograr los fines que el artículo propugna la LCCC prevé, en primer lugar, impulsar políticas de ahorro y eficiencia energética, con el objetivo de reducir el consumo final de energía al menos un $2 \%$ anual para llegar, como mínimo, al $27 \%$ en el año 2030 , excluyendo los usos no energéticos. La fijación de este objetivo de reducción del consumo final de energía en al menos un $2 \%$ fue impugnada ante el TC, y se dio la razón al recurrente, entendiendo que Catalunya se estaba extralimitando en sus competencias, lo que conllevó a su anulación. Los argumentos que llevaron a tal conclusión fueron los que ya nos resultan familiares, que Catalunya no podía concretar estos objetivos cuando el Estado aún no lo había hecho. Se trata de una interpretación que de nuevo merma las competencias autonómicas.

En la actualidad el Decreto Ley 16/2019, al que ya nos hemos referido, regula de nuevo esta cuestión, y en esta ocasión fija un objetivo menos ambicioso del $32,5 \%$ en lugar del $27 \%$ - y cita expresamente la legislación básica estatal como norma de referencia, a la que atender. Este objetivo es, al fin y al cabo, el que marca la UE en su nuevo marco legislativo, especialmente en el paquete "Energía Limpia para todos los Europeos". El texto catalán actual prevé: "promover las medidas necesarias en el ámbito del ahorro y la eficiencia energética para que el consumo final de energía el año 2030 sea un mínimo del $32,5 \%$ inferior respecto del tendencial, en el marco de la normativa estatal básica en materia de energía." Como vemos, no hace ninguna referencia al porcentaje de reducción de consumo final de energía anual, tan solo al global, fijando el objetivo como un mínimo, pudiendo ser superior, es decir, un porcentaje inferior, y haciendo referencia a que sea inferior del tendencial, y siempre teniendo en cuenta la legislación básica estatal. Con ello se logra 
mantener una concreción en términos de objetivos reducción del consumo final de energía.

La LCCC, propone, en segundo lugar, en su redacción inicial y actual, "promover las energías renovables, que deben desarrollarse, siempre que sea posible, aprovechando espacios ya alterados por la actividad humana, y minimizar así la ocupación innecesaria del territorio". Esto cabrá tenerlo en cuenta en relación con las instalaciones nuevas de energía eólica y solar fotovoltaica al elegir su emplazamiento.

En tercer lugar, la LCCC pretende impulsar un modelo energético en que el consumo de combustibles fósiles tienda a ser nulo, para que en 2030 se pueda alcanzar el $50 \%$ de participación de las energías renovables en el sistema eléctrico catalán para poder llegar al $100 \%$ de renovables en 2050 . Este objetivo, tras la revisión constitucional corrió la misma suerte que el primer propósito, en los mismos términos y con los mismos argumentos, por lo que se anula dicha concreción. El argumento sigue la misma lógica que el empleado anteriormente. La concreción de los objetivos no debe quedar en manos de las CCAA, sino que debe reservarse a las bases estatales. La nueva redacción del artículo que incorpora el Decreto ley 16/2019: "promover las medidas necesarias en el ámbito de las energías renovables para que el consumo eléctrico de Cataluña provenga -en un $50 \%$ el año 2030 y un $100 \%$ el año 2050- de esas fuentes renovables, priorizando la proximidad de la producción eléctrica de origen renovable a los centros de consumo" matiza el artículo derogado, ya no habla de un sistema energético catalán, sino de Catalunya, obvia la referencia expresa a la tendencia de que el consumo de combustible fósil sea nulo e incorpora como novedad el principio de proximidad de la producción eléctrica." En esta ocasión, sin embargo, la concreción sigue existiendo.

A continuación la LCCC contempla la adopción de medidas de carácter normativo que favorezcan el autoconsumo energético a partir de energías renovables y la participación de actores locales en la producción y distribución de energía renovable; el fomento de la generación de energía distribuida y nuevas opciones en distribución y contratación de suministros, y la implantación de redes de distribución de energía inteligentes y redes cerradas; 
y la promoción de la creación de un clúster de investigación y producción en energías renovables a partir de los centros de investigación en energías renovables presentes en Cataluña.

El autoconsumo energético a partir de energías renovables, así como la participación de actores locales en la producción y distribución de energía renovable, sin lugar a dudas facilitan la transición energética justa que se propugna. ${ }^{29}$ La utilización de fuentes de energía renovable ya se preveía por la Directiva 2009/72/CE y es la Directiva (UE) 2018/2001, de 11 de diciembre, la que regula actualmente el fomento del uso de la energía procedente de fuentes renovables. La Ley 24/2013, del Sector de la Energía (LSE) planteó el autoconsumo energético en el estado español - el cual debe ser diferenciado del sistema de energía distributiva - y lo regulo a través del Real Decreto 900/2015 que dio lugar a fuertes críticas, en gran medidas porque en vez de fomentar el autoconsumo energético de energías renovables, las trabas adminstrativas eran tales que generaba el efecto contrario. La desafortunada regulación quiso ser subsanada por parte del Real Decreto-ley 15/2018, de 5 de octubre, de medidas urgentes para la transición energética y la protección de los consumidores, que entre otras muchas cuestiones, puso luz sobre el autoconsumo energético, en términos de definición y de gestión. Además de establecer medidas contra la pobreza energética reguló el autoconsumo eléctrico renovable. Se cuestionó la justificación del uso de este instrumento el Real Decreto Ley - para regular esta cuestión, y posteriormente fue convalidado por el Congreso y tramitado como Proyecto de Ley por el procedimiento de urgencia. Las medidas de impulso al autoconsumo se vieron introducidas modificando el artículo 9 de la LSE.

En materia competencial la regulación entre Estado y CCAA del autoconsumo energético no ha sido del todo pacífica. En varias ocasiones el TC tuvo que pronunciarse al respecto, en relación con la regulación de esta materia en la LSE y, mientras que en las SSTC 72/2016, de 14 de abril y 60/2016, de 17 de

\footnotetext{
${ }^{29}$ Sobre estas cuestiones véase, Laura Presicce, "El periplo de la regulación del autoconsumo energético y generación distribuida en España: la transición de camino hacia la sostenibilidad", en RVAP, núm. 113, Enero-Abril 2019, pp. 181-221, y Susana Galera Rodrigo "Las entidades locales y su función en las políticas europeas de energía y clima. Una revolución silenciosa", en M.R. Alonso Ibáñez (dir.), Retos del desarrollo urbano sostenible e integrado, Tirant lo Blanch, Valencia, 2018, pp. 433-455.
} 
mayo, se consideró que el Estado era el competente para regular el autoconsumo energético en base a los artículos ya conocidos del 149.1.13 CE y 149.1.25 CE, la STC 68/2017, de 25 de mayo, dio un pequeño viraje al considerar que en el Real Decreto 900/2015 el Estado se había extralimitado en sus competencias, en los artículos 19 a 22, ya que la competencia para regular el procedimiento de inscripción de las instalaciones de autoconsumo ubicadas en su territorio se dejan al ámbito de las CCAA.

El Estado español ha aprobado recientemente el Real Decreto 244/2019, de 5 de abril, por el que se regulan las condiciones administrativas, técnicas y económicas del autoconsumo de energía eléctrica, que sustituye y deroga el mencionado RD 900/2015, y desarrolla en el ámbito estatal el favorecimiento del autoconsumo energético a partir de energías renovables.

Catalunya, de momento, no ha regulado sobre la materia aunque el Institut Català d'Energia vela por el fomento de este autoconsumo. ${ }^{30}$ Asimismo, existen iniciativas locales catalanas para producir i distribuir energía.

El artículo 19.2 LCCC prevé "para la transición energética hacia un modelo cien por cien renovable, desnuclearizado y descarbonizado, neutro en emisiones de gases de efecto invernadero" establecer un "plan de transición para el cierre, no más allá de 2027, de las centrales nucleares (...)", y "diseñar un sistema de tarifas que penalicen el sobreconsumo." Este objetivo fue impugnado ante el TC y, en los mismos términos que los apartados anulados anteriormente, la STC consideró que Catalunya no es competente para decidir cuándo deben cerrarse las centrales nucleares, ni para fijar tarifas en el sector eléctrico y gasístico. Por ello, declara inconstitucional este artículo, fundamentándolo en que es contrario a las bases estatales y considerando que la Comunidad autónoma carece de competencia para fijar tarifas del sector eléctrico y gasístico.

Recapitulando, en relación con los objetivos de "la transición energética hacia un modelo cien por cien renovable, desnuclearizado y descarbonizado con reducción del consumo de energía un $2 \%$ anual el cierre de las nucleares en 2027 , la reducción de combustibles fósiles al $50 \%$ en 2030 y a cero en $2050 "$

\footnotetext{
$30<$ http://icaen.gencat.cat/ca/energia/autoconsum/ > [Última consulta, 26 d'abril de 2020].
} 
considera que el objetivo en genérico "no pasa de ser una directriz programática constitucionalmente legítima amparada en el artículo 45 CE y 27 y 46 EAC pero, sin embargo, cuando detalla los objetivos, se extralimita al imponer objetivos concretos "detallados en términos mesurables y por tanto vinculantes". Considera que "todo ello es contrario a las bases estatales por no encontrarse recogido en ellas, la transición a un modelo energético 100\% renovable". La STC 87/2019 se refiere a las normas estatales que serían aplicables en los ámbitos en los que se fijan dichos objetivos, relacionados con el sistema energético, como son la Ley 24/2013, de 26 de diciembre, del Sector Eléctrico, la Ley 22/1973, de 21 de julio, de Minas y la Ley 25/1964, de 29 de abril, sobre energía nuclear. A estas normas les otorga un carácter materialmente básico, por lo que considera que deben imponerse. En todas ellas está permitido todo lo que la LCCC prohíbe, es decir, no avalan la legislación autonómica, por lo que la STC llega a la conclusión de anular. Considera que hay una "contradicción efectiva e insalvable entre estas normas estatales básicas y los objetivos concretos" y por lo tanto no puede considerarse un ejercicio legítimo de la competencia en materia de protección del medio ambiente. Des de mi punto de vista el título de protección ambiental debería jugar un papel de mayor relevancia que el que le otorga el TC en este ámbito. Aún así, la STC considera que estas normas exceden con mucho la perspectiva estrictamente medioambiental y aun energética. Afirma que "no pueden las CCAA decidir libre, aislada e individualmente si, en su caso cómo afrontan la "transición energética" y la fecha en que debe conseguirse ésta a modo de dies ad quiem. Solo el estado se encuentra en la posición y tiene las herramientas para decidir planificar esa transformación." En esta interpretación se está perdiendo la visión global y la necesidad de dar una respuesta a la problemática ambiental que suscita el cambio climático, unos desafíos y unos retos ambientales que deberían abordarse desde esa visión holística y no desde una visión fragmentada como en la que se fundamenta esta interpretación constitucional.

El apartado tercero del artículo 19, que se considera accesorio y conforme a la constitución, atribuye competencias al Instituto Catalán de la Energía impulsando y realizando, en colaboración con los departamentos de la 
Generalidad, los programas y actuaciones necesarios en materia de energías renovables y de ahorro y eficiencia energéticos para alcanzar los objetivos establecidos por la ley y actuando como impulsor de las actuaciones en este ámbito de las administraciones locales con competencias energéticas y preparando las estructuras conceptuales y tecnológicas necesarias para transformarse en una agencia catalana de la energía con capacidad de gobernanza, regulación y control sobre el Pacto nacional para la transición energética en Cataluña.

El apartado cuarto del mismo artículo 19, que establece que "el Gobierno no concederá permisos de exploración para la obtención de gas y petróleo de esquisto por fracturación hidráulica horizontal (fracking), incluida la relacionada con la obtención de gas metano de capas de carbón con utilización de fracturación inducida", es anulado por la STC. Este artículo, que había quedado suspendido por prohibir de manera absoluta e incondicionada el otorgamiento de permisos de exploración para trabajos que requieran la técnica del fracking, se considera que no se ajusta a la doctrina de las SSTC 8/2018 y 65/2018 por lo que lo declara inconstitucional y nulo. ${ }^{31}$ El TC aquí está siendo fiel a su jurisprudencia previa al respecto.

El Decreto Ley 16/2019 ha considerado oportuno reformular esta cuestión y en lugar de prohibir el fracking en su totalidad establece unas exclusiones y unas limitaciones para poder otorgar permisos de investigación para la obtención de gas y de petróleo de esquisto por fracturación hidráulica horizontal (fracking), incluyendo la relacionada con la obtención de gas metano de capas de carbón con utilización de fracturación inducida. La redacción actual de la ley prohíbe conceder estos permisos en suelo urbano o suelo urbanizable y a una distancia inferior a 500 metros de los núcleos urbanos. Además, prevé la limitación de este permiso a "los supuestos donde se garantice que no pueden resultar afectados: a) Los espacios que forman parte de la Xarxa Natura 2000; b) Los recursos hídricos superficiales o subterráneos y las zonas que hayan sido designadas como vulnerables a la contaminación por nitratos procedentes de

\footnotetext{
${ }^{31}$ En estas sentencias se declaraba la inconstitucionalidad de normativas autonómicas del País Vasco y Castilla-La Mancha que prohibían el fracking, de nuevo amparándose en los artículos 149.1.13 CE y 149.1.25 CE.
} 
fuentes agrarias; c) Las zonas que sean objeto de protección especial, dentro del ámbito del distrito de cuenca fluvial de Cataluña (DCFC).

En definitiva, Catalunya, no ha podido ejercer su autogobierno plenamente en esta materia pero a pesar de permitir esta actividad, no lo hace plenamente sino que limita ampliamente los lugares en los que se puede llevar a cabo con una finalidad claramente protectora del medio ambiente y de la salud de las personas.

A continuación, el apartado quinto del artículo 19 LCCC encomienda al Gobierno adoptar las propuestas normativas pertinentes, una vez acordado el Pacto nacional para la transición energética en Cataluña, con relación al autoconsumo de electricidad solar fotovoltaica, para favorecer la implantación de las tecnologías de generación eléctrica distribuida a los edificios, con una gestión activa de la demanda y producción de energía eléctrica y con el apoyo de las tecnologías de almacenamiento de energía, para reducir los consumos energéticos, maximizar las capacidades del sistema eléctrico y mejorar su sostenibilidad ambiental y económica global. Asimismo, el Gobierno debe modificar la legislación para agilizar la tramitación de la implantación de parques eólicos. La STC considera, en esta ocasión, como ya mencionamos anteriormente, que el Pacto nacional para la transición energética de Catalunya, es un instrumento de planificación, el cual no contempla objetivos concretos, por lo que la mera habilitación no vulnera el orden constitucional ni la distribución de competencias. La Disposición Adicional segunda de la LCCC prevé en el marco de la mitigación de las emisiones de gases de efecto invernadero en el ámbito de la energía que el Gobierno impulse la aprobación de este Pacto.

El Pacto Nacional para la Transición Energética (PNTE), fue aprobado por Acuerdo del Gobierno el 31 de enero de 2017, unos meses antes de la aprobación de la LCCC y plantea un nuevo escenario que fija como objetivo el cierre y el abandono de las fuentes energéticas de combustible fósil y de energía nuclear para lograr un sistema energético con energías cien por cien renovables, fundamentalmente de proximidad, desnuclearizado y neutro en emisiones de gases de efecto invernadero en el horizonte 2050, todo ello 
alineado con la LCCC. ${ }^{32}$ Por este motivo, plantea un nuevo modelo energético que pretende dar protagonismo a la ciudadanía poniéndolas en el centro, donde tanto ellas como las empresas pasen a ser "consumidoras activas con la posibilidad de poder consumir, generar, almacenar y vender energía eléctrica al mismo tiempo que gestionan su consumo". ${ }^{33}$ Este pacto fue aprobado junto con el Plan de la energía y cambio climático de Cataluña (2012-2020).

Por último, el apartado sexto del artículo 19 LCCC, al que ya nos referimos al inicio del trabajo al referirnos a los objetivos de mitigación, prescribe que "la planificación energética debe incorporar los objetivos de reducción de emisiones establecidos por la presente ley. Los planes de energía y de mitigación del cambio climático deben elaborarse de forma integrada". Este artículo también se ha visto afectado por la STC de tal modo que la redacción actual se ha incorporado con el Decreto 16/2019. En la actualidad, se excluye la referencia a los objetivos de reducción de emisiones, ya que la STC entiende que es inconstitucional, al pretender concretar objetivos en los planes energéticos. Por ello la redacción actual queda del siguiente modo: "La planificación energética y la de mitigación del cambio climático se deben elaborar de manera integrada. Hay que tener en especial consideración el principio de justicia social en aquellas personas, colectivos, sectores económicos y territorios que puedan resultar más afectados por la transición energética."

Queremos hacer especial hincapié en la introducción del principio de justicia social, que aunque ya se preveía tímidamente en el apartado primero en cuanto que exigía que se garantice el derecho de acceso a la energía como bien común, ahora se refuerza y se le da especial relevancia, por lo que podemos afirmar que se persigue una transición energética justa y así se menciona de forma expresa.

La Disposición final sexta, en relación con el artículo 19, determina el desarrollo de estrategias específicas en materia de energía al que se refiere,

\footnotetext{
32 En este enlace podemos encontrar todas las cuestiones que se han llevado a cabo en la Generalitat en relación con el Pacte nacional per a la Transició Energètica de Catalunya. $<$ http://icaen.gencat.cat/ca/plans programes/transicio energetica/ > [última consulta el 26 de abril de 2020].

${ }^{33}$ Exposición de motivos del Decreto Ley 16/2019.
} 
estableciendo el plazo de un año para que el departamento competente en materia de energía desarrolle varias estrategias específicas: a) El desarrollo de un marco normativo que favorezca el autoconsumo energético a partir de energías renovables; b) El fomento de la generación de energía distribuida y la implantación de redes de distribución de energía inteligentes; c) La promoción del modelo contractual de rendimiento energético con garantía de ahorro como forma prioritaria de colaboración pública y privada para la renovación energética de edificios y equipamientos públicos; d) El desarrollo e impulso de una estrategia catalana de infraestructuras de recarga de vehículo eléctrico que permita desplegar puntos de recarga vinculados a las viviendas y lugares de trabajo y profundizar en la formación de los instaladores, de los administradores de fincas y de los promotores de edificios ${ }^{34}$; e) La planificación y el despliegue de la red rápida estratégica para garantizar la cobertura de suministro en desplazamientos interurbanos con distancias máximas de 150 kilómetros o las que se determinen a medida que avance la tecnología de almacenamiento eléctrico.

La STC ha mantenido íntegramente la redacción de este artículo, por encontrarse en el plano de la planificación y abordar cuestiones genéricas. Sin embargo, aún no se han desarrollado todas las cuestiones que se apuntan.

El apartado a) se ve reflejado, en cierto modo en el Decreto Ley 16/2019, en su capítulo 4, dedicado a la "Regulación de la autorización de las instalaciones de producción de energía eléctrica proveniente de energía eólica y de energía solar fotovoltaica". Se compone de dieciocho artículos que regulan este tipo de instalaciones - parques eólicos y placas solares fotovoltaicas con unas potencias específicas ${ }^{35}$ - que se sitúan sobre el terreno en suelos clasificados

\footnotetext{
${ }^{34} \mathrm{http}: / /$ icaen.gencat.cat/es/plans programes/pirvec/ [última consulta 2 de maig de 2020].

35 a)Parques eólicos: instalaciones de producción de electricidad a partir de la fuerza del viento, de una potencia superior a $100 \mathrm{~kW}$ e inferior o igual en $50 \mathrm{MW}$, con o sin autoconsumo, constituidas por un aerogenerador o una agrupación de estos interconectados eléctricamente y con un único punto de conexión a la red de transporte o distribución de energía eléctrica. Forman también parte del parque eólico las infraestructuras de evacuación eléctrica, la subestación del parque y los accesos de nueva construcción o la modificación de los ya existentes.

b) Plantas solares fotovoltaicas: instalaciones de producción de electricidad a partir de la energía solar mediante el efecto fotoeléctrico, con o sin autoconsumo, de una potencia superior a $100 \mathrm{~kW}$ e inferior o igual en $50 \mathrm{MW}$, constituidas por un conjunto de módulos destinados a la captación de la energía solar interconectados eléctricamente y con un único punto de conexión a la red de transporte o de distribución de energía eléctrica. Forman parte también de la planta
} 
como no urbanizables, aunque también se le aplica a aquellas situada en terreno en otro tipo de suelo para la autorización energética y la evaluación de impacto ambiental. Asimismo, se exige a las personas interesadas en implantar un parque eólico o una planta solar fotovoltaica formular una consulta previa a la Ponencia de energías renovables sobre la viabilidad del emplazamiento proyectado para la instalación, a través de la Oficina de Gestión Empresarial (OGE) y adjuntando determinada documentación. La Ponencia, tras varias consultas, debe decidir sobre la viabilidad o no del proyecto. La sección segunda regula lo que es propiamente dicha la autorización. Esto es, las intervenciones administrativas necesarias para la implantación de los parques eólicos y las plantas solares fotovoltaicas (art. 12), que comprenden la autorización administrativa previa y de construcción (vertiente energética), la aprobación de un proyecto de actuación específica de interés público en suelo no urbanizable (vertiente urbanística y paisajística) la evaluación de impacto ambiental del proyecto del parque eólico o de la planta sola fotovoltaica cuando sea exigible (vertiente ambiental), y que se debe realizar sobre el conjunto del proyecto que incluye también, entre otros, la línea eléctrica de evacuación, la subestación del parque o la planta y los viales de acceso y de servicio. Se contempla la tramitación conjunta para un proyecto híbrido que combine las tecnologías fotovoltaica y eólica.

En relación con la EIA la ley atribuye a la Ponencia de energías renovables, a la que antes nos hemos referido, la competencia de emitir la declaración de impacto ambiental o informe de impacto ambiental del proyecto. Una vez realizados estos trámites y obtenidas las respectivas resoluciones se prevé el otorgamiento de la autorización sustantiva en materia de energía. Este otorgamiento se condiciona a que la persona titular haya obtenido previamente los permisos de acceso y conexión en las redes de transporte o distribución correspondientes, aunque esta previsión no es de aplicación a las instalaciones de autoconsumo sin excedentes. Este Decreto Ley también regula la garantía de restitución de los terrenos a su estado original. Cantidad que debe pagar para asegurar que cumplirá con dicha obligación cuando eléctrica y los accesos de nueva construcción o la modificación de los ya existentes. 
finalice la actividad (art.19); la autorización de explotación de los parques eólicos y las plantas solares fotovoltaicas - que deberá pedirse una vez acabada la construcción e inscribirla en el Registro de instalaciones de producción de energía eléctrica de Cataluña y en el Registro de autoconsumo de energía eléctrica, mediante la Oficina de Gestión Empresarial, aportando la documentación que especifique el portal de tramitación (art. 20); la transmisión de la autorización en materia de energía - para los que deben concurrir unos requisitos que detalla (art. 21); la caducidad y revocación de la autorización en materia de energía. Finalmente, este Decreto Ley en sus anexos incluye la documentación que se exige presentar para obtener las correspondientes autorizaciones tanto por la normativa energética, como por la normativa urbanística y la necesaria para la evaluación de impacto ambiental del proyecto.

Se trata de una regulación exhaustiva, como si de una ley se tratara, por lo que es cuestionable la utilización del instrumento del Decreto Ley par a regular estas cuestiones de este calado. Por ello, ha sido altamente criticado, puesto que ha impedido el trámite parlamentario y la participación pública en el proceso de elaboración. Cabrá ver si todo este procedimiento incentiva a quienes pretenden apostar por el autoconsumo y que sean pequeños productores $\mathrm{o}$, en cambio, los echa atrás. Podría ser recomendable prever un procedimiento simplificado para aquellas pequeñas instalaciones. Es cierto que esta norma se prevé para las instalaciones eólicas y solares fotovoltaicas de una potencia superior a $100 \mathrm{~kW}$ e inferior o igual en $50 \mathrm{MW}$, por lo que las inferiores y las superiores estarán excluidas.

c) Edificios y edificaciones

Otra de las materias reguladas en las políticas sectoriales y que ha sido cuestionada ante el TC son los edificios y las edificaciones y su eficiencia energética. En este ámbito de la energía relacionada con los edificios se han suscitado dudas de constitucionalidad. En primer lugar, se cuestiona el artículo 4 que define el "edificio de consumo energético casi nulo" como "un edificio con un nivel de eficiencia energética muy elevado, calculada de acuerdo con la metodología establecida por el anexo I de la Directiva 2010/31/UE, del Parlamento Europeo y del Consejo, de 19 de mayo, relativa a la eficiencia 
energética de los edificios. La cantidad casi nula o muy baja de la energía requerida debe estar ampliamente cubierta por energía procedente de fuentes renovables, incluida la energía producida in situ o en el entorno del edificio." Este artículo es declarado nulo por la STC 87/2019. Relacionada con esta definición también se impugna la Disposición Transitoria tercera y su apartado 2 que remite a reglamento la definición de "edificios de energía de consumo casi nulo". Estas cuestiones se impugnan por considerar que esta definición está ya fijada en la normativa estatal, en concreto en el Código Técnico de la Edificación, aprobado por Real Decreto 314/2006, de 17 de marzo, y en la disposición adicional segunda del Real Decreto 235/2013, de 5 de abril, por el que se aprueba el procedimiento básico para la certificación de la eficiencia energética de los edificios.

En relación con las edificaciones también se cuestionan las solicitudes de licencia de edificios nuevos y de edificios existentes sometidos a una gran rehabilitación, que regula la Disposición Adicional tercera y que exige que incluyan un diseño que cumpla los requisitos correspondientes a un edificio de consumo de energía casi nulo a partir del 1 de enero de 2020 si son de titularidad privada y a partir del 1 de enero de 2018 si son de titularidad pública. Además prevé que los departamentos competentes en materia de energía y vivienda del Gobierno deben establecer, en el plazo de seis meses desde la entrada en vigor de la ley, los requisitos que debe cumplir un edificio para ser considerado de consumo de energía casi nulo. Los edificios existentes con valor arquitectónico o histórico deben alcanzar los objetivos establecidos por esta disposición mediante una planificación específica y un régimen de excepcionalidades. Por otra parte, el Gobierno debe promover, mediante incentivos fiscales y ayudas, la adopción de medidas que permitan obtener la condición de edificio con consumo de energía casi nulo tanto en los edificios nuevos como en los edificios existentes sometidos a una gran rehabilitación.

La definición establecida en la LCCC consiste en una definición prácticamente idéntica a la dada por el Estado en el Real Decreto 56/2016 por lo que la Generalitat, tanto el gobierno como el Parlament, defienden que los preceptos impugnados son constitucionales ya que la definición de "edificio de consumo de energía casi nulo" es idéntica a la establecida en la disposición adicional 
cuarta del Real Decreto 56/2016, de 12 de febrero, sin que se argumente de contrario dónde residen las discrepancias con esta definición. Sin embargo, el recurrente considera que se invade y duplica la definición ya efectuada por el Estado. El abogado del Estado argumenta que la Comunidad autónoma no puede definir normativamente el concepto de "edificios de consumo energético casi nulo" ya que este concepto ha sido fijado en la normativa estatal, en concreto en la disposición adicional cuarta del Real Decreto 56/2016, de 12 de febrero, por el que se transpone la Directiva 2012/27/UE del Parlamento Europeo y del Consejo, de 25 de octubre de 2012, relativa a la eficiencia energética, en lo referente a auditorias energéticas, acreditación de proveedores de servicios y auditores energéticos y promoción de la eficiencia del suministro de energía. ${ }^{36}$ Una definición que, de acuerdo con la disposición adicional cuarta de este Real Decreto 56/2016, se ampara en el ejercicio de las competencias de las reglas 13,23 y 25 del art. 149. I CE.

El TC considera que "no existe un título competencia específico para el cumplimiento o transposición de normas europeas, sino que estas deben ser introducidas en el ordenamiento jurídico interno de acuerdo con el reparto de competencias efectuado en la Constitución y el bloque de constitucionalidad." Por lo que está primando el quién puede establecer dicha definición en el derecho interno, independientemente de si es acorde con la definición establecida por la UE, siendo este quién el Estado y no las CCAA, a través de la Ley de Ordenación de la Edificación y del Código Técnico de la Edificación. En definitiva, se anula la definición en discordia, sin más.

\section{d) Infraestructuras}

La LCCC se refiere a las infraestructuras en general en diferentes artículos en relación con distintos ámbitos. El artículo 21 se refiere a estas de forma concreta, en el marco de las políticas sectoriales, como aquellas en las que intervenir para mitigar y adaptar el cambio climático. En especial se dirige a

\footnotetext{
36 "Se define como edificio de consumo de energía casi nulo, en el ámbito de la Directiva 2010/31/UE del Parlamento Europeo y del Consejo, de 19 de mayo de 2010, relativa a la eficiencia energética de los edificios, aquel edificio con un nivel de eficiencia energética muy alto, que se determinará de conformidad con el anexo I de la citada Directiva. La cantidad casi nula o muy baja de energía requerida debería estar cubierta, en muy amplia medida, por energía procedente de fuentes renovables, incluida energía procedente de fuentes renovables producida «in situ» o en el entorno".
} 
"Ios gestores de las infraestructuras de puertos, aeropuertos, transporte terrestre, energía, residuos y agua de Cataluña que quieran acogerse a las ayudas, las bonificaciones y los beneficios fiscales relativos a actuaciones y proyectos de naturaleza ambiental, energética, de innovación o para una transición hacia una economía baja en carbono establecidos o gestionados por la Administración de la Generalidad" y les exige determinadas acreditaciones.

Este artículo también ha sido sometido a revisión constitucional. Concretamente se plantea la inconstitucionalidad relacionada con las infraestructuras portuarias al determinar que "el departamento competente en materia de medio ambiente debe desarrollar un plan de electrificación progresiva de los principales puertos para facilitar la conexión a la red eléctrica local de los barcos amarrados." (art. 21.4). Este apartado ha sido declarado inconstitucional, ya que se considera que la competencia en materia de puertos es una competencia estatal. En el recurso se alegaba que el Estado tiene atribuida la competencia sobre "puertos de interés general" por el artículo 149.1.20 CE. A pesar de alegarse que se entiende que la referencia del texto legal es a los puertos que no sean de interés general - el EAC reconoce esta competencia en el artículo 141.1. El TC llega a la conclusión de que "la expresa referencia en el art. 21.4 a los "principales puertos" como objeto del plan de electrificación progresiva no permite excluir los puertos de interés general existentes en la Comunidad Autónoma, sin duda "principales", sin transformar el precepto en otro distinto, resultado vedado para este Tribunal."

En la actualidad este apartado 4 ha sido redactado de nuevo, por el Decreto Ley 16/2019. En él se establece de forma clara que el Gobierno debe desarrollar un plan de electrificación progresiva de los puertos competencia de la Generalitat de Catalunya con el fin de facilitar la conexión a la red eléctrica local de los barcos amarrados" y añade "para el resto de puertos de Cataluña el Gobierno de la Generalidad debe impulsar los mecanismos de colaboración oportunos para que puedan disponer de esa conexión."

Asimismo, el Decreto Ley 16/2019 modifica el apartado 2 de este artículo, aunque no había sido objeto de análisis constitucional. La redacción actual es más amplia, en cuanto a los ámbitos sectoriales a los que se refiere ya que incluye: agricultura, ganadería, gestión forestal, pesca, energía, transporte, 
gestión de residuos, gestión de recursos hídricos, ocupación del dominio público marítimo terrestre, utilización del medio marino, turismo, ordenación del territorio urbano y rural, o de los usos del suelo; y los promotores de los proyectos constructivos de nuevas infraestructuras de puertos, aeropuertos, transporte terrestre y ferroviario, energía, residuos y agua que se desarrollen en Cataluña. En segundo lugar, elude la referencia expresa genérica a los objetivos de reducción de emisiones y amplia los términos del análisis de vulnerabilidad y de la evaluación ambiental a la que se debe someter.

e) Transporte y movilidad

El artículo 24 LCCC, dedicado al transporte y la movilidad también ha sido cuestionado. En particular, el apartado tercero: "el Gobierno debe promover las medidas necesarias en el sector de la automoción para que los vehículos motorizados nuevos no sean de combustión interna fósil a partir de 2030 y para que el sector de la automoción pase de un modelo exclusivo de caballos fiscales a uno de emisiones contaminantes." y el cuarto: "Debe reducirse en un $50 \%$ la dependencia de los combustibles fósiles, especialmente de los derivados del petróleo en el ámbito del transporte rodado y de los puertos de mercancías y deportivos en el horizonte del año 2040." Se pretende acabar con los vehículos de combustión interna fósil y reducir la dependencia de los combustibles fósiles en este ámbito, así como cambiar la manera de computar. Una vez pasado el filtro de constitucionalidad la STC ha considerado que las medidas establecidas para el sector de la automoción en el apartado tercero son acordes a la constitución y, por lo tanto, pueden conservarse, en tanto que no contiene mandatos y objetivos concretos, salvo el inciso final que es declarado nulo. En él se pide el tránsito de un modelo exclusivo de caballos fiscales a uno de emisiones contaminantes. Se considera que está sometido a la LOFCA. El apartado cuarto lo califica de inequívocamente imperativo y por lo tanto nulo, en tanto que vulnera la competencia estatal sobre transporte de viajeros y mercancías que concurran por más de una Comunidad autónoma.

El Decreto Ley 16/2019 también ha querido, en esta ocasión, ajustar las cuestiones anuladas en este ámbito y por ello ha modificado la redacción de los apartados tercero y cuarto del artículo 24 , sustituyendo la referencia a las medidas por la referencia expresa al deber del gobierno de establecer 
incentivos y promover acuerdos para lograr los objetivos marcados, de reducir y eliminar el uso de combustibles. Por lo tanto, ha cambiado la perspectiva inicialmente prevista. En primer lugar, encomienda al Gobierno que establezca los incentivos y promueva los acuerdos con el sector de la automoción que permitan alcanzar una transición hacia una movilidad eléctrica de manera que el año 2030 los nuevos turismos, vehículos comerciales ligeros y motocicletas que se pongan en circulación no utilicen combustibles fósiles. En segundo lugar, debe establecer incentivos y promover acuerdos con el sector del transporte rodado para alcanzar una reducción de la dependencia de los combustibles fósiles el año 2040 del 50\% respecto del año 2005.

\section{Los impuestos ambientales de mitigación y adaptación del cambio climático}

Una de las herramientas que plantea de forma innovadora la ley catalana es la incorporación de varios impuestos ambientales. La LCCC crea dos impuesto y desarrolla otro ya creado con anterioridad.

En primer lugar, los artículos 40 a 50 regulan el impuesto sobre las emisiones de dióxido de carbono de los vehículos de tracción mecánica, que ya existía previamente, puesto que se había creado por la ley 5/2017. Estos artículos que desarrollan la regulación de este impuesto fueron impugnados y se declararon, en su totalidad, acordes a la constitución y, en consecuencia en plena vigencia. La STC llega a la conclusión de que no estamos ante un impuesto ambiental sino ante un impuesto sobre el consumo de ciertos bienes para uso particular, lo cual no supone una doble imposición y, por lo tanto, es legal.

Sin embargo, a raíz de su aplicación se ha visto necesario modificar algunas cuestiones que quedaban desajustadas, por lo que la Ley 9/2019, de 23 de diciembre, introduce varias modificaciones, al ponerse en evidencia, tras su implantación, alguna deficiencia de la regulación como es la relativa a la regulación de una cuantificación alternativa de emisiones de dióxido de carbono para los vehículos en los que no se incluye esta información en la ficha técnica, como indica el preámbulo. Asimismo, en cuanto a su gestión también se han introducido cambios. 
Además la Generalitat se plantea desarrollar los otros dos impuestos. Por un lado, se fija como objetivo, en relación con el "Avantprojecte de llei de l'impost sobre les emissions portuàries de grans vaixells", grabar las emisiones de óxidos de nitrógeno (NOx) durante las maniobras de atraco y durante la estancia del barco en el muelle, de acuerdo con la disposición final decimosegunda de la Ley del cambio climático y, por el otro, a través del "Avantprojecte de llei de l'impost sobre les activitats econòmiques que generen gasos amb efecte d'hivernacle" crea un impuesto para modificar conductas que comporten externalidades negativas sobre el medio ambiente (disposición adicional 11 de la LCCC). Las actividades afectadas serían: las que tienen instalaciones dentro del marco del régimen de comercio de derechos de emisión de la UE (Directiva 2003/87/CE del Parlamento Europeo y del Consejo, de 13 de octubre) y las instalaciones que están sometidas al trámite de evaluación de impacto ambiental (anexo I.1 de la Ley 20/2009, aunque no tengan instalaciones sujetas a la Directiva 2003/87/CE).

En ambos supuestos se ha iniciado la tramitación de la consulta pública y se preveía en el plan normativo que se aprobaría por el gobierno entre el segundo semestre de 2019 y el primero de 2020, sin embargo parece que aún no se ha tramitado ningún texto al respecto. Por lo tanto, de momento, a pesar de parecer ambiciosa la propuesta impositiva no está siendo aplicable de forma efectiva en su totalidad.

\section{La Comisión interdepartamental del Cambio climático}

La LCCC dedica el capítulo IV a la Administración en materia de cambio climático, que incluye al Gobierno, los departamentos de la Generalitat y sus organismos dependientes, la Comisión Interdepartamental del Cambio Climático, la Mesa Social del Cambio Climático y el Comité de Expertos sobre Cambio Climático. Además regula la participación de la Administración local en las políticas climáticas; planificación general, compensación territorial, simplificación y racionalización administrativas y financiación de los proyectos; la contratación verde; y la colaboración y cooperación internacionales.

Ninguno de estos artículos fue objeto del recurso de inconstitucionalidad contra la LCCC pero consideramos oportuno detenernos en la Comisión Interdepartamental de Cambio Climático en tanto que se ha promulgado el 
Decreto 33/2020, de 18 de febrero, por el que se establecen la composición y el régimen de funcionamiento de la Comisión Interdepartamental del Cambio Climático y sobre el Fondo Climático y la Comisión del Fondo Climático. Este decreto responde al desarrollo reglamentario que establece la ley 16/2017. Cabe apuntar que tanto un órgano como el otro ya existían con anterioridad a dicha ley. En 2006, se creó la Comisión Interdepartamental del Cambio Climático $^{37}$

El Decreto 33/2020 concreta la composición y el régimen de funcionamiento de la Comisión Interdepartamental del Cambio Climático, por un lado, y por el otro regula el Fondo Climático y la Comisión del Fondo Climático. Es destacable en relación con la composición de ambas comisiones que se exige velar por la representación equilibrada de hombres y mujeres tanto para las personas titulares como para las suplentes, con el objetivo de lograr la paridad de género.

Esta regulación permite avanzar un poco más en la aplicación efectiva de la LCCC, aún así, sigue siendo insuficiente.

\section{El Fondo Climático}

En el marco del capítulo VI de la LCCC y bajo el título "otros instrumentos para el cumplimiento de los objetivos de la ley" el artículo 51 regula el llamado Fondo Climático. En marzo 2017 se creó el Fondo de lucha contra el cambio climático, que poco después cambiaría de nombre adoptando el de Fondo Climático. ${ }^{38}$

Se trata de un "fondo de carácter público, con personalidad jurídica adscrito al departamento competente en materia de cambio climático, y que tiene como objetivo convertirse en un instrumento necesario para la ejecución de políticas y acciones de mitigación y adaptación al cambio climático." Se trata de una figura innovadora y reveladora que una vez se ponga en funcionamiento puede traer beneficios para revertir el cambio climático. Su aprobación no ha sido

\footnotetext{
${ }^{37}$ Mediante el Decreto 573/2006, de 19 de diciembre, de reestructuración parcial del Departament de Medi Ambient i Habitatge i bajo la dependencia de aquel Departament, con el prpósito que fuera el órgano de coordinación e impulso de la acción de Gobierno en esta materia.

${ }^{38}$ La Ley 4/2017, del 28 de marzo, de presupuestos de la Generalitat de Catalunya para el 2017, en su DA 9 creó el "Fons de lluita contra el canvi climàtic".
} 
pacífica y fue impugnado, en parte: el inciso final del apartado 1 que acabamos de reproducir y las letras a y $\mathrm{b}$ del apartado 3 , que regula las fuentes de financiación de este Fondo. Estas fuentes son, en primer lugar, los ingresos procedentes de los instrumentos establecidos por el capítulo V. El 100\% de la recaudación del impuesto sobre las actividades económicas que generan dióxido de carbono y del impuesto sobre las emisiones portuarias de grandes barcos, que crean esta ley se destina a nutrir este Fondo Climático y el $50 \%$ de los ingresos obtenidos del impuesto sobre las emisiones de dióxido de carbono de los vehículos de tracción mecánica, en todo caso, deben destinarse al Fondo Climático. En segundo lugar, los ingresos procedentes de la participación en sistemas de comercio de derechos de emisión de gases de efecto invernadero de la Unión Europea, o de otros instrumentos de fiscalidad climática de ámbito estatal. En tercer lugar, la parte de los ingresos de las asignaciones tributarias del impuesto sobre la renta de las personas físicas para finalidades de interés social que correspondan a la Generalitat y que esta destine a la protección del medio. $\mathrm{Y}$, por último, cualquier otra fuente de recursos económicos que el Gobierno considere adecuada.

La STC 87/2019, tras su análisis, no considera que el inciso del apartado primero vulnere la Constitución por lo que permite su desarrollo reglamentario, que establecerá su funcionamiento. Sin embargo, sí que llega a la conclusión de que el artículo 51.3 b) relativo a la financiación del fondo, perturba la competencia del estado para decidir interferencias ilegítimas sobre el destino de los propios recursos, por lo que declara nulos los ingresos procedentes de "la participación en sistemas de comercio de derechos de emisión de gases de efecto invernadero de la Unión Europea, o de otros instrumentos de fiscalidad climática de ámbito estatal", como ya podíamos deducir.

La Disposición Final 5 detalla, en relación con el reglamento que establezca el funcionamiento del Fondo Climático, que, "transitoriamente, hasta que no estén desarrollados los instrumentos de fiscalidad ambiental, debe incorporar los ingresos obtenidos de la subasta de derechos de emisión del régimen de comercio de derechos de emisión de gases de efecto invernadero que se acuerden con el Estado y una partida presupuestaria ordinaria para la lucha contra el cambio climático." Este inciso "los ingresos obtenidos de la subasta de 
derechos de emisión del régimen de comercio de derechos de emisión de GEl" también ha sido declarado nulo por la STC 87/2019, en los términos que ya conocemos. Considera además que "la mención de un "acuerdo con el estado" igualmente hipotético no permite sanar la vulneración competencial que representa disponer sobre recursos y fondos ajenos."

El Decreto Ley 16/2019 en este ámbito ha añadido un nuevo apartado al artículo 51, el quinto, permitiendo que se destinen recursos económicos del Fondo Climático a la dotación de los medios técnicos y humanos necesarios para su gestión, cuestión que hasta el momento no estaba prevista.

Por otra parte, el Decreto 33/2020, como vimos también regula el Fondo Climático y la Comisión del Fondo Climático. En relación con el Fondo climático regula la financiación y su gestión, en los términos que indica la LCCC. Recordemos que los recursos económicos de este fondo deben ir destinados a proyectos o actuaciones de mitigación y adaptación al cambio climático. La atribución de estos recursos se harán de acuerdo con las prioridades de actuación del Fondo, que corresponde decidir a la Comisión Interdepartamental mencionada, con la asistencia de la Comisión del propio Fondo y que se debe tomar atendiendo a la disponibilidad económica, la planificación sectorial y el análisis coste-eficiencia, como dispone la ley. El reglamento concreta, por una parte, que "para aplicar los criterios indicados, la Comisión del Fondo Climático tiene que facilitar a la Comisión Interdepartamental del Cambio Climático la información técnica de base en materia de planificación sectorial vigente, el análisis coste-eficiencia, las emisiones de gases con efecto invernadero y el análisis de vulnerabilidad de los diferentes sectores y sistemas" , y por la otra, que el análisis coste-eficiencia tiene que ser motivada y justificada basándose en los criterios siguientes: a) Potencial de reducción de emisiones de GEI; b) Potencial de reducción de la vulnerabilidad ante los impactos del cambio climático; c) Beneficios de tipo social; d) Eficiencia económica; e) la identificación de barreras financieras, tecnológicas o de otro tipo que puedan ser un obstáculo para el logro de los objetivos establecidos en la LCCC. Además, prohíbe la financiación de actuaciones dirigidas al cumplimento de las obligaciones exigibles en la normativa vigente cuando el beneficiario tenga la consideración de empresa que realiza una actividad económica o aquellas que 
puedan suponer una subvención o aportación considerada como ayuda de Estado. Esperamos ver este Fondo en activo lo antes posible.

Este reglamento también determina la composición de la Comisión del Fondo Climático, sus funciones, su régimen de funcionamiento y el régimen de sus sesiones. Consideramos que la existencia y el funcionamiento de este fondo puede ser un buen impulso para mitigar y adaptar el cambio climático.

En definitiva, a pesar de declarar un inciso del artículo inconstitucional el funcionamiento del Fondo Climático está validado. No obstante, en la actualidad no se está usando, puesto que las fuentes de financiación principales no aportan ninguna cantidad por el momento.

\section{El régimen de comercio de derechos de emisión}

Por último, cabe mencionar que el artículo 52 de la LCCC que regula el régimen de comercio de derechos de emisión también se cuestionó ante el TC, concretamente en los términos que prevé el apartado 1 en el que se atribuye a la Generalitat, en concreto al departamento competente en materia de cambio climático "la autorización, la supervisión, el control y el seguimiento en Catalunya de todas las actividades incluidas en el régimen de comercio de derechos de emisión de la Unión Europea, transitoriamente hasta que se adopte un nuevo instrumento más eficaz de lucha contra el cambio climático." También fue impugnado el apartado 3 por el que "el Gobierno debe establecer por reglamento los mecanismos de habilitación, acreditación de verificadores y certificación de personas físicas que puedan cumplir las tareas de verificación, de acuerdo con la normativa europea, así como la supervisión de sus actuaciones." La STC tras su análisis lleva a cabo una lectura restringida del artículo 52.1, ya que interpreta que las referencias del comercio de emisión que hace deben ser acordes con las competencias que les atribuye la ley 1/2005 a Catalunya. Por lo tanto, no lo declara nulo pero lo interpretar de este modo. En cuanto al articulo 52.3 considera, en relación con los verificadores, que la ENAC (Entidad nacional de Acreditación) es el único organismo que puede realizar verificaciones. Aún así, considera que no es un régimen básico y que, 
por lo tanto, puede regularse. En definitiva, realiza una interpretación acorde con la constitución y la Ley 1/2005.

\section{CONCLUSIONES}

Primera. La emergencia climática es una realidad y son necesarios instrumentos normativos para mitigar y adaptar el cambio climático, mediante el establecimiento de objetivos, herramientas y medidas adecuadas. El escenario actual plantea nuevos retos que se deben afrontar con firmeza, desde las distintas estancias y promover un cambio que permita revertir la situación, mitigar y adaptar el cambio climático y lograr una transición energética justa.

Segunda. Las CCAA ejercen un papel fundamental, junto con el resto de actores, en el logro de estos objetivos. La LCCC impulsó la primera regulación en el estado español con ambición y fue recurrida ante el TC que la revisó y la recortó, por entender que a pesar de ser una norma sustancialmente ambiental estaba invadiendo otras competencias de titularidad estatal. Esta STC es una más de la línea jurisprudencial seguida en los últimos tiempos que tiende a la recentralización de competencias en manos del Estado, propiciando un vaciado de competencias autonómicas y a su vez una desprotección ambiental importante. El sistema competencial español fragmentado agudiza esta problemática ya que dificulta poder abordar la cuestión del cambio climático de forma holística. A esto se le suma la tendencia a favorecer el desarrollo económico en detrimento de la protección medioambiental.

A pesar de los recortes que ha supuesto la STC 87/2019, ello no ha impedido que la ley se haya desarrollado en algunos términos - aunque escasos después de tres años de su vigencia y que se hayan reformulado algunas cuestiones anuladas. Sin embargo, es cierto que tras el filtro de constitucionalidad se han reducido las ambiciones iniciales, en especial, en relación con los objetivos concretos de reducción de los GEI y de transición energética, lo que se traduce en una merma del autogobierno autonómico.

Tercera.- Todas las cuestiones de la LCCC que apelan a objetivos genéricos se han considerado constitucionales, pero en cambio todos los que suponen una mínima concreción, vinculación, prohibición, que involucre a otras materias más 
allá de la protección ambiental, sobre todo del ámbito energético, han sido anuladas, por entender que deben reservarse a la regulación del Estado. Ello ha conllevado, por un lado, que cuando se han reformulado se haya tomado como referencia los objetivos marcados por la UE o que se haya sometido expresamente a lo dictado por el Estado y, por el otro, que otras cuestiones hayan quedado en el aire. Por ejemplo, Catalunya no tiene calendario para lograr los objetivos de reducción de los GEl, mientras que Andalucía Baleares lo conservan por no cuestionarse su constitucionalidad, lo cual no tienen ningún sentido. Si se aprueba el PLCCTE del Estado en los términos que está redactado el objetivo de reducción de GEI intermedio se fija en el $20 \%$, respecto a 1990, para 2030. Esto supone la mitad que pretendía Catalunya para la misma fecha, a pesar que el objetivo final de 2050, es lograr la neutralidad, pero ¿cómo se logrará? El objetivo catalán de cerrar las centrales nucleares para el 2027 también ha quedado en el aire, así como la posibilidad de establecer un sistema tarifario que penalice el sobreconsumo. Además, el objetivo de reducir el consumo final de energía al menos en un $2 \%$ anual hasta llegar al $27 \%$ desaparece fijándose un objetivo final de $32,5 \%$, acorde con la UE. La prohibición sobre fracking se recupera, aunque ya no total sino limitada. Todas las cuestiones que implican los derechos de emisión se anulan o se someten a la ley 1/2005. Otras cuestiones, como hemos visto, han sido reinterpretadas por la ST. Al fin y al cabo se trata de un ejemplo más de recentralización de competencias y de desprotección ambiental.

Cuarto. Afirmamos, que a pesar de esta revisión constitucional la ley es plenamente vigente y aplicable, aunque, menos ambiciosa. Aún así se mantienen instrumentos con un alto calado que pueden suponer un gran impulso para lograr los objetivos, como son los impuestos ambientales y el Fondo climático. Sin embargo, es necesario e imprescindible que se acelere el desarrollo de la ley, se apruebe el PLCCTE en trámite y la ley europea de cambio climático y que se aplique de forma efectiva la LCCC, ya que ya vamos tarde y la emergencia climática avanza sin pausa y sin tregua.

\section{BIBLIOGRAFÍA}

Alenza García, José Francisco, "Vulnerabilidad ambiental y vulnerabilidad climática" en RCDA, vol. 10 núm. 1, 2019, pp. 1-46. 
Borrás Pentinat, Susana y Villacencio Calzadilla, Paola (eds.), El Acuerdo de París sobre cambio climático: ¿Un acuerdo histórico o una oportunidad perdida?, Arazandi, Cizur Menor, 2018.

Casado Casado, Lucía, La recentralización de competencias en materia de protección del medio ambiente, Generalitat de Catalunya, Institut d'Estudis de l'Autogovern, 2018.

Cocciolo, Endrius, "La unión de la energía y la gobernanza del sistema tierra en el antropoceno: Una cuestión constitucional”, RCDA, vol. 6 núm.1, 2015 pp. 144.

De la Varga Pastor, Aitana, "Estudio de la ley catalana 16/2017, de 1 de agosto, de cambio climático, y análisis comparativo con otras iniciativas legislativas subestatales, $R C D A$, vol. 9, núm. 2 (2018).

Fernández de Gatta, Dionisio, "El ambicioso pacto verde europeo", en Actualidad Jurídica Ambiental, núm. 101, sección comentarios, de 12 de mayo de 2020. ISSN: 1989-5666; NIPO: 832-20-001-3.

Galera Rodrigo, Susana, "Las entidades locales y su función en las políticas europeas de energía y clima. Una revolución silenciosa", en M.R. Alonso Ibáñez (dir.), Retos del desarrollo urbano sostenible e integrado, Tirant lo Blanch, Valencia, 2018, pp. 433-455.

Jaria Manzano, Jordi, La constitución del Antropoceno, Tirant lo Blanch, 2020. Jaria Manzano, Jordi, "Jurisprudencia constitucional en materia de protección del medio ambiente (segundo semestre 2019)", RCDA Vol. X Núm. 2 (2019).

Lampis, Andrea, "Vulnerabilidad y adaptación al cambio climático: debates acerca del concepto de vulnerabilidad y su medición", en Cuadernos de Geografía, vol. 22, no 2, 2013, pp. 17-33.

Presicce, Laura, "El periplo de la regulación del autoconsumo energético y generación distribuida en España: la transición de camino hacia la sostenibilidad", en RVAP, núm. 113, Enero-Abril 2019, pp. 181-221. 
Riechmann, Jorge, "Calentamiento climático. ¿Cómo se calcula su impacto?", en Nuria del Viso (coord.) Cambio climático: un reto social inminente, fuhem, Madrid, 2005.

Riechmann, Jorge, "La crítica ecosocialista al capitalismo", Revista Integra Educativa, v.6 La paz, dic. 2013.

Rodríguez Beas, Marina, "La incidencia del acuerdo de París en las políticas públicas catalanas frente al cambio climático: la ley 16/2017, de 1 de agosto, del cambio climático", RCDA, vol. 9, núm. 2 (2018).

Rodríguez Beas, Marina, "El conflicto competencial sobre cambio climático entre España y Cataluña: avances y retrocesos a la luz de la reciente Sentencia del Tribunal constitucional 87/2019, de 20 de junio, sobre la Ley 16/2017, de 1 de agosto, de cambio climático", A\&C, Revista de Direito Administrativo \& Constitucional, núm. 77, 2019 pp. 59-96.

Rodriguez Beas. Marina, "Derecho y políticas ambientales en Catalunya (segundo semestre 2017), RCDA Vol IX Núm. 2 (2017). 